NBER WORKING PAPER SERIES

\title{
SURVIVAL AMBIGUITY AND WELFARE
}

Frank N. Caliendo

Aspen Gorry

Sita Slavov

Working Paper 23648

http://www.nber.org/papers/w23648

\author{
NATIONAL BUREAU OF ECONOMIC RESEARCH \\ 1050 Massachusetts Avenue \\ Cambridge, MA 02138 \\ August 2017
}

We thank Shantanu Bagchi, Scott Condie, Francisco Gomes, Geng Li, Erzo Luttmer, Olivia Mitchell, and Eytan Sheshinski for helpful comments. This research was supported by the U.S. Social Security Administration through grant \#RRC08098400-09 to the National Bureau of Economic Research as part of the SSA Retirement Research Consortium. The findings and conclusions expressed are solely those of the authors and do not represent the views of SSA, any agency of the Federal Government, or the National Bureau of Economic Research.

At least one co-author has disclosed a financial relationship of potential relevance for this research. Further information is available online at http://www.nber.org/papers/w23648.ack

NBER working papers are circulated for discussion and comment purposes. They have not been peer-reviewed or been subject to the review by the NBER Board of Directors that accompanies official NBER publications.

(C) 2017 by Frank N. Caliendo, Aspen Gorry, and Sita Slavov. All rights reserved. Short sections of text, not to exceed two paragraphs, may be quoted without explicit permission provided that full credit, including $\left({ }^{\circ}\right.$ notice, is given to the source. 
Survival Ambiguity and Welfare

Frank N. Caliendo, Aspen Gorry, and Sita Slavov

NBER Working Paper No. 23648

August 2017

JEL No. D80,D91,H55

\section{ABSTRACT}

Nearly all life-cycle models adopt Yaari's (1965) assumption that individuals know the survival probabilities that they face. Given that an individual's exact survival probabilities are likely unknown, we explore the implications of relaxing this assumption. If there is no annuity market, then the welfare cost of survival ambiguity is large and regressive. Individuals would pay as much as $1 \%$ of total lifetime consumption for immediate resolution of ambiguity and the bottom income quintile is 4 times worse off than the top quintile. Alternatively, with the availability of competitive annuity contracts, survival ambiguity is welfare improving because it allows competitive insurance companies to pool risk across survival types. Even though Social Security and annuities share some properties, Social Security does not help to hedge survival ambiguity.

Frank N. Caliendo

Department of Economics and Finance

Utah State University

Logan, UT 84322-3565

frank.caliendo@usu.edu

Aspen Gorry

John E. Walker Department

of Economics

Clemson University

228 Sirrine Hall

Clemson, SC 29631

aspen.gorry@gmail.com
Sita Slavov

Schar School of Policy and Government

George Mason University

3351 Fairfax Drive, MS 3B1

Arlington, VA 22201

and NBER

sslavov@gmu.edu 


\section{Introduction}

Starting with Yaari's (1965) classic model of survival uncertainty, numerous papers establish that annuitization protects individuals against longevity risk. However, in practice, private annuity markets are limited and individuals often fail to annuitize their wealth even when it would appear to be in their interest to do so (see, e.g., Mitchell, Poterba, Warshawsky, and Brown (2001)). A common explanation for why private annuity markets are so thin is asymmetric information, which gives rise to adverse selection. For example, Finklestein and Poterba (2004) document that individuals sort into different types of annuity contracts based on observed mortality. Adverse selection is often cited as a rationale for a universal Social Security system that effectively forces all individuals to purchase annuities. ${ }^{1}$

Yaari (1965), Sheshinski (2008) and the other papers on which these arguments are based generally make two crucial assumptions about survival uncertainty. ${ }^{2}$ First, individuals are risk neutral over the length of life. Second, individuals know the survival probabilities that they face as they plan for the future. Bommier (2006) examines the implications of relaxing the first assumption and shows that risk aversion over length of life can lead to dynamic inconsistency under certain conditions. In this paper we study the implications of relaxing the second assumption. We argue that individuals are unlikely to know the exact survival probabilities that they face because many factors that determine these probabilities are unobservable. In particular we assume that individuals face ambiguity about the length of their lives. ${ }^{3}$

Interestingly, the effect of survival ambiguity on welfare (expected utility) depends crucially on the structure of the insurance market. Ambiguity about survival probabilities has a significant welfare cost when there are no private annuity markets. However, it is welfare improving when there are private annuity markets because it allows additional risk pooling by insurance companies. Together, these findings imply that competitive annuities provide larger welfare gains under ambiguity than with only survival risk, in contrast to the welfare gains from annuities in a setting with asymmetric information. Finally,

\footnotetext{
${ }^{1}$ Some recent papers have called this rationale into question. Caliendo, Guo, and Hosseini (2014) show that in general equilibrium, Social Security crowds out bequests, and this crowding out effect can offset the welfare improvement from mandatory annuitization. Hosseini (2015) shows that most of the welfare gain from Social Security is offset by the fact that Social Security crowds out private annuity purchases by high-mortality individuals, thereby worsening adverse selection and driving up prices in private annuity markets. Brown, Kapteyn, Luttmer, and Mitchell (2016) review a number of factors that could reduce the demand for annuities relative to Yaari's full annuitization result.

${ }^{2}$ Beyond survival uncertainty, Yaari made a variety of other assumptions such as expected utility maximization, intertemporally separable utility, actuarially fair annuities, and market completeness. These assumptions have been relaxed systematically by Davidoff, Brown, and Diamond (2005) among others.

${ }^{3}$ We use the terms uncertainty and risk interchangeably, as both refer to the case in which the distribution of a random variable is known. We reserve the word ambiguity for the case in which the distribution of a random variable is unknown. In our context, the length of life is a random variable and individuals do not know the exact distribution from which their survival is drawn. In our terminology, a "survival function" is the probability of surviving to each age, which is one minus the c.d.f. over the random date of death.
} 
we find that while Social Security may insure against longevity risk, it does not insure against survival ambiguity.

In order to quantify the welfare cost of survival ambiguity, the amount of ambiguity facing individuals must be measured. To address this challenge, we make two assumptions. First, there are only two survival types: high and low, where the survival probability of the former strictly exceeds that of the latter at each age. Second, the length of life is a compound lottery: individuals don't know how long they will live and they don't know their exact survival function, but they know the set of survival functions from which theirs is drawn. Of course, in reality there are potentially more than two types (we consider a continuum of types in the appendix) and a compound lottery is only one way to model ambiguity (we could have instead assumed that the set of survival functions is unknown). The advantage of these assumptions is that they allow us to use mortality data to identify the extent of the survival ambiguity that individuals face. As an application, by allowing individuals to form prior expectations based on their income quintile, we can identify their priors and the two survival functions by fitting survival data for each income quintile (Cristia (2009)) to an expected survival function for each quintile. Here, the resulting survival function for each quintile is a probabilistic weighted average of the survival functions of the two underlying survival types. This procedure generates a measure of survival ambiguity by income quintile.

We first consider the case in which annuity markets are closed. Given the lack of demand for private annuities, this is the typical case considered in the macroeconomics and public economics literatures. In this setting, consumption and saving decisions under ambiguity are distorted away from their full information counterparts where the individual fully optimizes based on a known survival function. ${ }^{4}$ Quantitatively, our measured ambiguity generates a welfare cost that is large and regressive. Individuals would pay as much as $1 \%$ of total lifetime consumption to know their survival function, and ambiguity hurts the bottom income quintile 4 times more than it hurts the top quintile. ${ }^{5}$ The welfare cost of survival ambiguity is regressive because the poor rationally believe there is a good chance that they are a low

\footnotetext{
${ }^{4}$ In addition to survival ambiguity, individuals face a variety of uncertainties and difficulties when planning and saving for retirement. While not considered here, many of these issues have been tackled previously in the literature, including uncertainty about medical expenses (De Nardi, French, and Jones (2010)), career length risk (Grochulski and Zhang (2013), Caliendo, Casanova, Gorry, and Slavov (2016)), wage and interest rate risk (Chai, Horneff, Maurer, and Mitchell (2011), Vidangos (2009)), as well as policy uncertainty (Gomes, Kotlikoff, and Viceira (2007), Luttmer and Samwick (2012), Caliendo, Gorry, and Slavov (2016), Kitao (2016)) and limits on financial literacy (Lusardi and Mitchell (2007), Lusardi and Mitchell (2008), van Rooij, Lusardi, and Alessie (2012), Lusardi, Michaud, and Mitchell (2017), Ameriks, Caplin, and Leahy (2003), Campbell (2006)).

${ }^{5}$ Edwards (2008) calculates that individuals would give up about 6 months of mean life span in exchange for a one-year reduction in the standard deviation. While this has a similar flavor to our results, he does not consider the case of survival ambiguity; individuals in his model know the probabilities of surviving to future ages. Likewise, there is a large literature (both theoretical and empirical) that seeks to assess the value of a life through cost-benefit analysis of life saving technologies (e.g., Bommier and Villeneuve (2012)). We depart from this literature by focusing on the value of information about survival probabilities.
} 
survival type, which causes them to save very little relative to what they would save if they knew they were a high type. Essentially, ambiguity causes a painful "undersaving" problem among the poor who are the high survival type.

Our calculations can be interpreted as a lower bound on the cost of ambiguity for two reasons. First, we do not assume that individuals are ambiguity averse. ${ }^{6}$ Survival ambiguity is costly in our model not because people dislike ambiguity per se, but because it causes potentially large distortions to consumption-saving decisions. Individuals either save too much or they save too little relative to the case in which survival probabilities are known. Adding a distaste for ambiguity would further increase the welfare cost of ambiguity. Second, we do not assume individuals are prone to any type of irrational behavior. We follow the approach of Sheshinski (2008) in considering the standard model with rational individuals and information constraints. Individuals in our model have rational prior beliefs about the survival probabilities that they face, and they rationally update those beliefs according to Bayes' rule. This assumption preserves the dynamic consistency property of the original model - an example of a more general theorem developed by Epstein and Le Breton (1993). Moreover, this assumption allows us to model ambiguity in a way that is consistent with empirical evidence showing that subjective survival beliefs in surveys are close to average survival rates in the data (Hurd and McGarry (1995)). In other words, individuals in our model cope with ambiguity in a way that minimizes its welfare cost. ${ }^{7}$ However, we potentially overstate the welfare cost by assuming there are only two survival types and by assuming individuals form survival expectations based solely on their position in the income distribution. ${ }^{8}$

In addition to the welfare issues described above, distinguishing between survival risk and ambiguity has important implications for saving rates. For more than 50 years economists have debated whether the rich save a larger fraction of their lifetime income than the poor. Dynan, Skinner, and Zeldes (2004) confirm that the rich do indeed save more. ${ }^{9}$ We find that differential mortality with ambiguity is a

\footnotetext{
${ }^{6}$ Dimmock, Kouwenberg, Mitchell, and Peijnenburg (2016) estimate that half of the population are ambiguity averse, and they argue that ambiguity aversion helps to explain stock market participation and portfolio decisions that otherwise appear puzzling.

${ }^{7}$ Brown, Kapteyn, Luttmer, and Mitchell (2016) quantify the degree to which individuals are cognitively constrained in their internal valuation of annuities. We abstract from limits on cognition.

${ }^{8} \mathrm{In}$ an extension, we test the robustness of our welfare results to the binary ambiguity calibration procedure. We allow for a continuum of survival types so that the individual's true survival function may take any form, rather than just two types. When we redo our structural calibration with this assumption we find that, while the welfare cost of ambiguity is smaller in this case than in the case of binary ambiguity, the regressivity result persists.

${ }^{9}$ They use a three-period life-cycle model to compare the saving behavior of the top and bottom income quintiles and they conclude that a bequest motive, when coupled with an assumption that earnings are mean reverting across generations, can potentially explain why the rich save more. Rich parents want to bequeath large sums of wealth to their relatively poor kids, whereas poor parents are less interested in bequeathing wealth to their relatively rich kids. They also find that means-tested welfare programs could explain the saving rate gap, but late-life health expense shocks cause the poor to save more because paying for a fixed health expense would require aggressive saving by the poor. They do not consider survival
} 
potential source of variation in saving rates. Ambiguity about mortality risk erases some but not all of the gap in saving rates that is otherwise generated by differential mortality.

Next we consider the case in which competitive annuity contracts exist. While survival ambiguity reduces welfare in the model without annuities, ambiguity increases welfare in a world with annuities. Even though ambiguity distorts decisions away from optimal decisions in an environment where individuals know their type, it allows competitive insurance companies to pool risk across survival types since neither individuals or companies have information about an individual's type. This contrasts with a world of full information in which competitive insurance companies would separate individuals by survival type. This risk sharing ensures that welfare is higher with ambiguity than without ambiguity. Brugiavini (1993) makes a similar point, showing that when individuals do not know their survival probabilities, they purchase annuities early in life in order to insure against this added layer of uncertainty. This is also reminiscent of a point made by Sheshinski (2008), in which he considers the superiority of long-term annuity contracts that provide risk sharing across survival classes relative to short-term contracts that do not.

The two main results that we have documented thus far-ambiguity is welfare reducing in the absence of annuities but is welfare improving the presence of annuities - combine to create a final result: the welfare gains from competitive annuities are understated in Yaari-style models that feature only survival risk. This has important implications for how we think about the insurance value of annuitization. Annuitization provides a hedge against survival risk as past studies have established, but with ambiguity annuities also pool risk across survival type. They insure survival risk by utilizing the assets of the deceased to provide a premium to surviving annuitants and they insure survival type by paying a premium that reflects pooling across unknown survival types. For instance, while Davidoff, Brown, and Diamond (2005) and others have documented large welfare gains from annuitization in various extensions of Yaari's model, these estimates understate the value of annuitization by focusing only on survival risk while abstracting from ambiguity. Likewise, the large effort in the literature to rationalize the lack of demand for annuities typically assumes that annuities only insure survival risk rather than confronting the possibility that they insure both survival risk and survival type. ${ }^{10}$ Hence, while asymmetric information about survival risk can rationalize thin annuity markets, ambiguity about survival risk makes thin annuity markets even more puzzling.

Finally, given that a rationale for Social Security is that it provides longevity insurance, we consider

ambiguity.

${ }^{10}$ See Brown (2007) and Brown, Kling, Mullainathan, and Wrobel (2008) for a review of this literature. 
whether Social Security helps individuals insure against survival ambiguity and whether this insurance is greater for poor than rich. The answer to both questions is no. Social Security and annuities both pay benefits for as long as individuals live and both can provide an implicit rate of return that exceeds the market return by making use of the fact that benefits are paid only to survivors. Ceterus paribus, this feature of Social Security can deliver large welfare gains. However, Social Security does not provide a hedge against survival ambiguity because benefits are the same whether or not individuals face survival ambiguity under current Social Security policy. That is, the program pools survival types in the payment of benefits independent of any information individuals have about their survival type. Moreover, a Social Security system that is more generous to the poor does not change the fact that Social Security benefits are not conditioned on one's (lack of) information about survival type, so the program does not affect the individual's willingness to pay for immediate resolution of ambiguity.

Our approach contrasts with other approaches to studying how individuals update information about survival probabilities. Other methods include modeling health status and adverse health shocks more directly. For instance, Reichling and Smetters (2015) allow mortality probabilities to be stochastic, and they show that negative health shocks that reduce life expectancy and are correlated with negative income shocks will tend to dramatically reduce the demand for annuity contracts. In contrast, our model implies that annuities are even more valuable in the presence of ambiguity. ${ }^{11}$ Cocco and Gomes (2012) analyze the demand for a potential financial instrument that they call a "longevity bond" whose returns would be correlated with longevity shocks. The individual welfare gain from a longevity bond is similar in spirit to our calculations of the value of knowing one's longevity risk. The difference is that individuals in their model are hit with aggregate longevity shocks each period, whereas individuals in our model don't know their longevity type and update their beliefs as they age. The distributional effects of the two models are distinctly different: in their model high-income individuals with above average longevity benefit more from hedging longevity shocks, whereas in our model low-income individuals benefit more from knowing their survival type. ${ }^{12}$

Finally, more dramatic departures from the way we model information could include individuals whose health types are partially known by say family history or genetic testing, or there could be individuals

\footnotetext{
${ }^{11}$ Our paper differs from Reichling and Smetters in a few technical ways as well. First, to introduce stochastic mortality probabilities, they compute 3-state health transition probabilities for the entire population, with different survival probabilities tied to each health state. We take a different approach: we structurally calibrate the degree of ambiguity facing individuals of each income quintile, and we assume individuals never fully learn their true survival probabilities but instead they Bayesian update their beliefs as they age.

${ }^{12}$ Huang, Milevsky, and Salisbury (2011) also study a model with stochastic mortality rates. But as in the other papers cited above, they do not address the welfare cost of survival ambiguity.
} 
that misestimate their longevity risk due to some behavioral bias. Our method utilizes the well-known empirical fact that mortality risk is strongly connected to income class (e.g., Cristia (2009)). While behavioral biases about survival ambiguity in a non-expected utility framework may help to explain various savings puzzles as in Groneck, Ludwig, and Zimper (2014) and Heimer, Myrseth, and Schoenle (2016), we seek to understand the welfare implications of survival ambiguity in a rational framework with only information constraints. ${ }^{13}$

\section{Theory}

This section develops our concept of survival ambiguity and shows how to compute welfare costs in a simple theoretical framework. The next section extends the simple model with survival ambiguity to a life-cycle consumption-saving framework. All derivations are in Appendix A.

We consider an environment where individuals face survival risk and differ by survival type, where the survival type captures the survival probabilities that a given individual faces. Time is indexed by $t$. For simplicity, time starts at $t=0$ and ends no later than $t=T$. Survival risk implies that the decision problem will end suddenly at $t=t_{1} \in[0, T]$. When the individual does not face ambiguity, the stop date $t_{1}$ is a continuous random variable, with probability density $\phi\left(t_{1}\right)$ and sample space $[0, T]$ where $\int_{0}^{T} \phi\left(t_{1}\right) d t_{1}=1$

In this environment, survival ambiguity means that the individual does not know their survival function. That is, beyond the survival risk that arises from the fact that the sudden stop $t_{1}$ is a random variable, the decision maker does not know the density function over which this random variable is defined.

To begin, we assume that there are just two survival types, high and low. That is, $\phi\left(t_{1}\right) \in\left\{\underline{\phi}\left(t_{1}\right), \bar{\phi}\left(t_{1}\right)\right\}$. With just two types we can let $p=\operatorname{prob}\left[\phi\left(t_{1}\right)=\underline{\phi}\left(t_{1}\right)\right]$ be the probability that the individual is the low type and $(1-p)=\operatorname{prob}\left[\phi\left(t_{1}\right)=\bar{\phi}\left(t_{1}\right)\right]$ be the probability that the individual is the high type. Although we stick to this simple formulation throughout the paper, we consider the case where $\phi\left(t_{1}\right)$ can be any convex combination of $\underline{\phi}\left(t_{1}\right)$ and $\bar{\phi}\left(t_{1}\right)$ in Appendix B. In both cases, our setup models survival ambiguity as a compound lottery.

The control variable $u(t)$ is unconstrained, and without loss of generality the state variable $x(t)$ is constrained only at the initial and maximum points in time, $x(0)=x_{0}$ and $x(T)=x_{T}$. Stopping point uncertainty together with ambiguity about that uncertainty can all be compressed neatly into a discount

\footnotetext{
${ }^{13}$ Gan, Gong, Hurd, and McFadden (2015) find that observed wealth levels are better explained by a model featuring individual-level subjective survival beliefs than by a model with average survival rates from the data. Also see Gan, Hurd, and McFadden (2005).
} 
function in the objective functional (see Appendix A for a derivation), and the dynamic optimization can be state as follows.

For any concave, continuously differentiable payoff function $f(t, u(t), x(t))$ and constraint function $g(t, u(t), x(t))$, and with survival functions $\underline{\Phi}(t)=\int_{t}^{T} \underline{\phi}\left(t_{1}\right) d t_{1}$ and $\bar{\Phi}(t)=\int_{t}^{T} \bar{\phi}\left(t_{1}\right) d t_{1}$ for notational convenience, the decision maker solves

$$
\max _{u(t)_{t \in[0, T]}}: J=\int_{0}^{T}[p \underline{\Phi}(t)+(1-p) \bar{\Phi}(t)] f(t, u(t), x(t)) d t
$$

subject to

$$
\begin{gathered}
\frac{d x(t)}{d t}=g(t, u(t), x(t)) \text { for } t \in[0, T] \\
x(0)=x_{0}, x(T)=x_{T} .
\end{gathered}
$$

This is the problem that a decision maker would solve from the perspective of $t=0$. As time advances, the initial solution remains optimal if and only if the individual updates the likelihood of being a low survival type using Bayes' rule (Epstein and Le Breton (1993)). In other words, Bayesian updating ensures that decision making under survival ambiguity is dynamically consistent (see Appendix A for a proof). ${ }^{14}$

In order to define a measure of the welfare cost of survival ambiguity, we define solutions for three separate control problems, each subject to the same constraints as above. In the first problem the decision maker faces ambiguity as above. In the second problem the decision maker knows that he is the low type, $\Phi(t)=\underline{\Phi}(t)$. Finally, in the third problem the decision maker knows that he is the high type, $\Phi(t)=\bar{\Phi}(t)$. Hence,

$$
\begin{gathered}
\left\{u^{*}(t \mid p), x^{*}(t \mid p)\right\}=\arg \max \left\{\int_{0}^{T}[p \underline{\Phi}(t)+(1-p) \bar{\Phi}(t)] f(t, u(t), x(t)) d t\right\} \\
\{\underline{u}(t), \underline{x}(t)\}=\arg \max \left\{\int_{0}^{T} \underline{\Phi}(t) f(t, u(t), x(t)) d t\right\} \\
\{\bar{u}(t), \bar{x}(t)\}=\arg \max \left\{\int_{0}^{T} \bar{\Phi}(t) f(t, u(t), x(t)) d t\right\} .
\end{gathered}
$$

Next define the objective functionals associated with these three problems:

$$
J^{*}(u, x)=\int_{0}^{T}[p \underline{\Phi}(t)+(1-p) \bar{\Phi}(t)] f(t, u(t), x(t)) d t
$$

\footnotetext{
${ }^{14}$ Sozou (1998) also considers Bayesian learning about survival uncertainty. He shows that Bayesian learning, together with specific assumptions about prior beliefs, can cause the decision maker to discount the future hyperbolically. We show that Bayesian learning is a necessary condition for dynamically consistent decision making under survival ambiguity.
} 


$$
\begin{aligned}
& \underline{J}(u, x)=\int_{0}^{T} \underline{\Phi}(t) f(t, u(t), x(t)) d t \\
& \bar{J}(u, x)=\int_{0}^{T} \bar{\Phi}(t) f(t, u(t), x(t)) d t .
\end{aligned}
$$

With these definitions, we can define the welfare cost of ambiguity.

Definition 1 (Welfare Cost of Ambiguity). The cost of ambiguity $\Delta$ is the fraction of the optimal control that the decision maker would give up to know $\Phi(t)$.

$$
p \underline{J}(\underline{u}(1-\Delta), \underline{x})+(1-p) \bar{J}(\bar{u}(1-\Delta), \bar{x})=J^{*}\left(u^{*}, x^{*}\right)=p \underline{J}\left(u^{*}, x^{*}\right)+(1-p) \bar{J}\left(u^{*}, x^{*}\right) .
$$

It is useful to note the variance of survival ambiguity. For any moment in time $t, \Phi(t)$ is a random variable with variance ${ }^{15}$

$$
\sigma^{2}(t \mid p)=(1-p) p[\underline{\Phi}(t)-\bar{\Phi}(t)]^{2}
$$

This implies that to make a fair comparison of the cost of ambiguity across two decision makers that holds the level of ambiguity constant for two different levels of beliefs, one who faces $p=p^{\prime}$ and the other $p=p^{\prime \prime}$, requires

$$
\sigma^{2}\left(t \mid p^{\prime}\right)=\sigma^{2}\left(t \mid p^{\prime \prime}\right) \Longrightarrow\left(1-p^{\prime}\right) p^{\prime}=\left(1-p^{\prime \prime}\right) p^{\prime \prime} \Longrightarrow p^{\prime}=1-p^{\prime \prime}
$$

Of course, two different decision makers could face different degrees of ambiguity in actuality.

\section{Life-Cycle Model without Annuities}

We now apply our simple framework to a life-cycle consumption saving problem in which annuity markets are closed. Consider an individual who is born at $t=0$ and passes away no later than $t=1$. We think of $t=0$ as age 25 and $t=1$ as age 100. Survival to any future date is uncertain. The individual's survival type is either low, $\underline{\Phi}(t)$, or high, $\bar{\Phi}(t)$. The individual faces ambiguity about his survival type. He initially believes that he is a low type with probability $p$ and a high type with probability $1-p$. The probabilities are updated as the individual survives using Bayes' rule.

\footnotetext{
${ }^{15}$ This is derived by simplifying the following equation

$$
\begin{aligned}
\sigma^{2}(t \mid p) & =p\{\underline{\Phi}(t)-[p \underline{\Phi}(t)+(1-p) \bar{\Phi}(t)]\}^{2}+(1-p)\{\bar{\Phi}(t)-[p \underline{\Phi}(t)+(1-p) \bar{\Phi}(t)]\}^{2} \\
& =p(1-p)^{2}[\underline{\Phi}(t)-\bar{\Phi}(t)]^{2}+(1-p) p^{2}[\bar{\Phi}(t)-\underline{\Phi}(t)]^{2}
\end{aligned}
$$
}

etc. 
The individual's utility function is CRRA, $c(t)^{1-\sigma} /(1-\sigma)$, and in addition to mortality risk, the individual discounts future utility due to impatience at rate $\rho$. Consumption spending is $c(t)$ and the stock of assets is $k(t)$, which earns interest at the risk-free rate $r$. The individual starts with no assets and he cannot plan to hold debt at the maximum possible age. Finally, the flow of disposable income is $y(t)$.

The individual solves ${ }^{16}$

$$
\max _{c(t)_{t \in[0,1]}}: J^{*}=\int_{0}^{1}[p \underline{\Phi}(t)+(1-p) \bar{\Phi}(t)] e^{-\rho t} \frac{c(t)^{1-\sigma}}{1-\sigma} d t
$$

subject to

$$
\begin{gathered}
\frac{d k(t)}{d t}=r k(t)+y(t)-c(t) \\
k(0)=0, k(1)=0 .
\end{gathered}
$$

The solution to this problem is

$$
c^{*}(t \mid p)=\frac{\int_{0}^{1} e^{-r v} y(v) d v}{\int_{0}^{1} e^{-r v+(r-\rho) v / \sigma}[p \underline{\Phi}(v)+(1-p) \bar{\Phi}(v)]^{1 / \sigma} d v} e^{(r-\rho) t / \sigma}[p \underline{\Phi}(t)+(1-p) \bar{\Phi}(t)]^{1 / \sigma} .
$$

On the other hand, if the individual knows his survival type at date 0 , then he would follow either

$$
\underline{c}(t)=\frac{\int_{0}^{1} e^{-r v} y(v) d v}{\int_{0}^{1} e^{-r v+(r-\rho) v / \sigma} \underline{\Phi}(v)^{1 / \sigma} d v} e^{(r-\rho) t / \sigma} \underline{\Phi}(t)^{1 / \sigma}
$$

or

$$
\bar{c}(t)=\frac{\int_{0}^{1} e^{-r v} y(v) d v}{\int_{0}^{1} e^{-r v+(r-\rho) v / \sigma} \bar{\Phi}(v)^{1 / \sigma} d v} e^{(r-\rho) t / \sigma} \bar{\Phi}(t)^{1 / \sigma} .
$$

Using our definition from the previous section, the welfare cost of ambiguity $\Delta$ satisfies

$$
\begin{aligned}
& p \int_{0}^{1} \underline{\Phi}(t) e^{-\rho t} \frac{[\underline{c}(t)(1-\Delta)]^{1-\sigma}}{1-\sigma} d t+(1-p) \int_{0}^{1} \bar{\Phi}(t) e^{-\rho t} \frac{[\bar{c}(t)(1-\Delta)]^{1-\sigma}}{1-\sigma} d t \\
= & \int_{0}^{1}[p \underline{\Phi}(t)+(1-p) \bar{\Phi}(t)] e^{-\rho t} \frac{c^{*}(t \mid p)^{1-\sigma}}{1-\sigma} d t
\end{aligned}
$$

\footnotetext{
${ }^{16}$ We follow the standard approach of assuming that utility is additively separable across time. Bommier (2006) and Bommier and Villeneuve (2012) argue that this implies risk neutrality with respect to the length of life (or it implies risk aversion with an infinite weight on life relative to consumption - a "priceless life"). While we stick with standard preferences in order to understand the consequences of extending the classic Yaari (1965) model to include ambiguity, a possible extension would be to consider non-additive preferences. While there is less scope in our paper for considering risk aversion over lifespan because lifespan is exogenous, risk aversion would affect intertemporal consumption decisions and welfare.
} 
or

$$
\Delta(p)=1-\left(\frac{\int_{0}^{1}[p \underline{\Phi}(t)+(1-p) \bar{\Phi}(t)] e^{-\rho t} c^{*}(t \mid p)^{1-\sigma} d t}{p \int_{0}^{1} \underline{\Phi}(t) e^{-\rho t} \underline{c}(t)^{1-\sigma} d t+(1-p) \int_{0}^{1} \bar{\Phi}(t) e^{-\rho t} \bar{c}(t)^{1-\sigma} d t}\right)^{1 /(1-\sigma)} .
$$

As an application, we calculate the welfare cost of survival ambiguity for individuals in different income groups. It is well known that low income individuals face lower survival rates at every age than high income individuals (Cristia (2009)). Both groups face ambiguity about their survival probabilities, so it is interesting to determine for which group ambiguity is more costly.

We show welfare results for two sets of parameterizations. In the first parameterization, we do not hold the variance of ambiguity constant across income groups, letting the mortality data determine how much ambiguity the different income groups face. This approach has the advantage of imposing very little structure on the parameterization of ambiguity, but the resulting parameterization will not typically generate the same amount of ambiguity across income groups. Therefore, in the second parameterization we ignore the mortality data and limit ourselves to fair comparisons that assign the same degree of ambiguity to the different income groups. Both methods generate the same conclusion: those who face lower chances of survival (the poor) experience much larger welfare losses from ambiguity about their survival than those who face higher chances of survival (the rich).

Throughout both parameterizations, we will set the coefficient of relative risk aversion to $\sigma=3$ (which is the same value used by Dynan, Skinner, and Zeldes (2004)), the utility discount rate to $\rho=0$, and the real interest rate to $2.9 \%$ per year following the 2013 report of the Social Security Trustees, which in our model (where time is normalized onto the unit interval) implies $r=75 * 0.029=2.175$.

\subsection{Parameterization \#1 (Structural Calibration)}

In this section we jointly calibrate the boundary survival functions $\underline{\Phi}(t)$ and $\bar{\Phi}(t)$ as well as the ambiguity that each group faces, $p_{i}$. Individuals are separated into income quintiles $i \in\{1,2,3,4,5\}$, where $i=1$ is the poorest quintile and $\Phi_{i}(t)$ is the unconditional survival function of quintile $i$ in the actual data. We use Bagchi's (2014) calculations of the data provided by Cristia (2009) and solve the following calibration problem

$$
\min _{\underline{\Phi}(t), \bar{\Phi}(t), p_{i}} \mathcal{L} \equiv \sqrt{\sum_{i=1}^{5} \int_{0}^{1}\left\{\Phi_{i}(t)-\left[p_{i} \underline{\Phi}(t)+\left(1-p_{i}\right) \bar{\Phi}(t)\right]\right\}^{2} d t}
$$


subject to a set of flexible (logistic) survival functions for the two survival types,

$$
\begin{aligned}
& \underline{\Phi}(t)=1-\frac{1}{1+\exp \left[-x_{1}\left(t-x_{2}\right)\right]} \\
& \bar{\Phi}(t)=1-\frac{1}{1+\exp \left[-x_{3}\left(t-x_{4}\right)\right]} .
\end{aligned}
$$

This calibration procedure involves 9 parameters to jointly calibrate. The results are found in Table 1 and Figure 1. Table 1 contains the parameters of the survival functions of the different survival types and the priors for each group. Notice in Figure 1 the close fit of the expected survival probabilities that model individuals in each quintile face (dashed lines) with the survival probabilities that actual individuals in each quintile face (solid lines). The dashed lines are formed by taking a weighted average of $\underline{\Phi}(t)$ and $\bar{\Phi}(t)$, where the weights are the $p_{i}$ values. The structure that we have imposed-the logistic shape of the two survival functions - is both minimal and flexible enough to capture key dynamics in the data.

\begin{tabular}{l}
\hline \hline Table 1. Joint Calibration of Survival Functions and Binary Ambiguity \\
Shape Parameters of Logistic Survival Curves: \\
$\qquad \begin{array}{l}x_{1}=9.17 \quad x_{2}=0.51 \quad x_{3}=15.23 \quad x_{4}=0.78 \\
\text { Probabilities of Low Survival Type by Income Quintile: } \\
p_{1}=44.4 \% \quad p_{2}=30.7 \% \quad p_{3}=25.5 \% \quad p_{4}=19.1 \% \quad p_{5}=8.9 \%\end{array}$ \\
Note: $p_{1}$ corresponds to the poorest quintile and $p_{5}$ corresponds to the richest quintile.
\end{tabular}

As mentioned already, by letting the data determine the probabilities $p_{i}$, we are not requiring a fair comparison between income groups. The variance of ambiguity is maximized when $p=1 / 2$ and when the gap between $\underline{\Phi}(t)$ and $\bar{\Phi}(t)$ is maximized. In Figure 2 we see that our structural calibration places more ambiguity on the poor than on the rich at all ages. Therefore, any inequality in welfare losses across income groups will be partly due to differences to the degree of ambiguity. However, in actuality, ambiguity may not be constant across income groups, and so welfare analysis based on the current strategy is valuable.

In Table 2 we report the welfare cost of ambiguity by income quintile. Figure 3 plots consumption profiles under ambiguity relative to consumption profiles when survival type is known in advance. We 
draw two conclusions from Table 2. First, the welfare losses from ambiguity about survival uncertainty are large for all income groups. These losses are on par or larger than some estimates of the costs of business cycle fluctuations (Lucas (2003)) as well as the costs of idiosyncratic household financial risks (Vidangos (2009)). Second, ambiguity about survival uncertainty imposes larger costs on the poor than the rich. The poorest quintile experiences a welfare loss that is 4 times larger than that of the richest quintile. ${ }^{17}$

Table 2. Welfare Cost of Binary Ambiguity by Income Quintile

$$
\Delta\left(p_{1}\right)=1.08 \% \quad \Delta\left(p_{2}\right)=0.81 \% \quad \Delta\left(p_{3}\right)=0.69 \% \quad \Delta\left(p_{4}\right)=0.53 \% \quad \Delta\left(p_{5}\right)=0.25 \%
$$

Note: $p_{1}$ corresponds to the poorest quintile and $p_{5}$ corresponds to the richest quintile.

\subsection{Parameterization \#2 (Fair Comparison)}

In this section we consider fair comparisons of individuals who differ by expected survival type but face the same variance of ambiguity at each age. We use the boundary survival functions $\underline{\Phi}(t)$ and $\bar{\Phi}(t)$ that were calibrated in the previous section, but now we make comparisons between individuals with probabilities $p^{\prime}$ and $p^{\prime \prime}$ such that $\sigma^{2}\left(t \mid p^{\prime}\right)=\sigma^{2}\left(t \mid p^{\prime \prime}\right)$, which implies $p^{\prime}=1-p^{\prime \prime}$.

Figure 4 plots consumption profiles for two such individuals. The variance of ambiguity is dynamic across age, but it is fixed across individuals. An individual who faces a $70 \%$ chance that he is a low survival type (i.e., a poor individual with $p=70 \%$ ), experiences a welfare loss of $1.26 \%$ from ambiguity about survival uncertainty. On the other hand, an individual who faces the same variance of ambiguity but faces only a $30 \%$ chance that he is a low survival type (i.e., a rich individual with $p=30 \%$ ), experiences a welfare loss of $0.79 \%$ from ambiguity about survival uncertainty. Notice that even after making a fair comparison of individuals, the welfare loss is still regressive.

Figure 5 is a graph of $\Delta(p)$, where we have highlighted one example of a fair comparison. Recall that $p=1 / 2$ maximizes $\sigma^{2}(t \mid p)$. But, notice that $\Delta(p)$ does not peak at $p=1 / 2$ as one might expect. Holding the variance of ambiguity constant, the cost of ambiguity is larger at high $p$ values than at low $p$ values.

\footnotetext{
${ }^{17}$ Some may question whether our maintained assumption of Bayesian learning is appropriate for all income quintiles. The concern could be that the rich have more contact with the medical industry and would therefore have more chances for learning about their survival type. However, we do not have a complicated information aquisition problem in this model. Individuals update their priors only based on survival to the next date. If the rich learn more rapidly than the poor, then ambiguity would be even more regressive than we have estimated in our model.
} 
Ambiguity is costly because it causes distortion to consumption and saving decisions relative to a world in which the individual has full information about survival probabilities. Under full information, the individual correctly optimizes based on known survival probabilities, while under ambiguity the individual applies expected survival probabilities in decision making and updates his beliefs toward the high type as he survives. Our welfare measure captures the individual's willingness to pay for immediate resolution of ambiguity.

The intuition behind the regressivity of ambiguity is as follows. No matter what value of $p$ we consider on the open interval $(0,1)$, the individual saves too little if he is in fact a high type, and saves too much if he is in fact a low type. Even though any individual (rich or poor) can make oversaving errors and undersaving errors in our model, the undersaving errors are more costly. The poor make bigger undersaving errors and therefore have larger welfare costs than the rich, because the poor plan for a shorter life expectancy and are more ill-prepared if they turn out to live a long time.

Given this, one may ask why undersaving errors are more costly than oversaving errors. After all, both errors involve the immiseration of the individual over some part of the life cycle. Undersaving errors cause immiseration of the individual when old, while oversaving errors cause immiseration while young. But the answer is that undersaving creates painful distortions to consumption at a time when consumption is already relatively low and so mistakes have large utility effects, whereas oversaving creates painful distortion when consumption is high relative to its level late in life and so such an error doesn't matter as much.

\subsection{Policy Implications: Social Security}

Notice that the present value of disposable income $\int_{0}^{1} e^{-r v} y(v) d v$ cancels out of the right hand side of $\Delta(p)$. Therefore the disposable income path is irrelevant for the calculation of $\Delta(p)$. Whether someone is rich or poor does not itself affect one's willingness to sacrifice a given fraction of lifetime consumption in exchange for information about survival probabilities. What matters is the probability of being a low survival type, $p$. Therefore, the welfare cost of survival ambiguity is regressive only because this probability is inversely related to income.

In our simple model, Social Security would enter the individual's optimization problem through the $y(v)$ term. The individual would pay taxes while working and collect benefits when retired. Social Security has the same impact on $y(v)$ regardless of the presence of ambiguity since taxes and benefits do not depend on one's survival type even when it is known. Whether the individual views such mandatory saving as welfare improving depends on the size of the benefits relative to the taxes paid, and the expected duration 
of time over which these benefits are collected. For a typical parameterization of our model, even if we abstract from wage heterogeneity and Social Security's redistributive role, Social Security can provide large welfare gains through its longevity insurance role because it pays benefits as a life annuity. These benefits carry an implicit return that can be superior to the market rate of interest. But regardless of whether Social Security is welfare improving, it is apparent that Social Security does not provide a hedge against survival ambiguity. In other words, whether Social Security causes increased welfare or decreased welfare to the individual — by causing an overall increase or decrease to the term $\int_{0}^{1} e^{-r v} y(v) d v$ - this term cancels out in the calculation of $\Delta(p)$. Intuitively, even if Social Security improves welfare by providing a life annuity, the additional utility gain from being able to optimize consumption based on one's survival type is unchanged. So while our paper is silent on the issue of whether Social Security improves welfare, the cost of survival ambiguity is the same whether Social Security exists or not and therefore it does not provide a hedge against survival ambiguity.

We can take our discussion a step further by asking whether the presence of ambiguity has any effect on the mandatory annuitization role of Social Security. In a standard model with mortality risk only and no ambiguity, we know from past studies that mandatory annuitization through a fully-funded Social Security system can improve lifetime welfare because the mandatory annuitization feature creates higher implicit returns than can be found in the capital market. ${ }^{18}$ In our model with survival ambiguity, the government cannot know the survival type of a given individual, but it wouldn't face any aggregate uncertainty either. Hence, the government simply provides benefits with an above market implicit return just as in the case without survival ambiguity, and an individual facing survival ambiguity would be willing to give up (ex ante) the same fraction of lifetime consumption to participate in a mandatory annuitization program as would individuals who know their survival type. In other words, the welfare gain from mandatory annuitization through Social Security is unaltered by survival ambiguity.

\subsection{Saving Rates}

For more than 50 years economists have debated whether the rich save a larger fraction of their lifetime income than the poor. Researchers using modern data sets have confirmed that the rich do indeed save more (Dynan, Skinner, and Zeldes (2004)). In addition to the explanations given by Dynan, Skinner, and Zeldes and others, differential mortality is another potential source of variation since the rich would tend

\footnotetext{
${ }^{18}$ This well known result goes away once we include general equilibrium bequest income as in Caliendo, Guo, and Hosseini (2014), and may go away if individuals are borrowing constrained, but these are separate issues that we do not want to focus on here.
} 
to save more because they expect to live longer. What is less clear, however, is how much of the saving rate gap that can be attributed to differential mortality will survive after accounting for a realistic degree of ambiguity. Using our structural calibration to measure the degree of ambiguity by income quintile, we find that ambiguity reduces but does not eliminate the saving rate gap that could otherwise be caused by differential mortality.

To illustrate this point, we define the saving rate as the fraction of lifetime income that is not consumed when young

$$
s=\frac{\int_{0}^{1} e^{-r v} y(v) d v-\int_{0}^{t} e^{-r v} c(v) d v}{\int_{0}^{1} e^{-r v} y(v) d v}
$$

where $t$ is the age of retirement. Without loss of generality, we normalize $\int_{0}^{1} e^{-r v} y(v) d v=1$, and we set $t=40 / 75$ (which corresponds to a retirement age of 65 if work starts and 25 and death occurs no later than 100). For comparison, we compute saving rates for individuals living with ambiguity and for individuals who know that they are either a low type or a high type

$$
\begin{gathered}
s^{*}(p)=1-\int_{0}^{40 / 75} e^{-r v} c^{*}(v \mid p) d v \\
\underline{s}=1-\int_{0}^{40 / 75} e^{-r v} \underline{c}(v) d v \\
\bar{s}=1-\int_{0}^{40 / 75} e^{-r v} \bar{c}(v) d v
\end{gathered}
$$

With ambiguity, the saving rate in quintile $i$ is $s^{*}\left(p_{i}\right)$. Without ambiguity, the average saving rate in quintile $i$ is $s_{i}=p_{i} \underline{s}+\left(1-p_{i}\right) \bar{s}$. For the poorest quintile (quintile 1 ) with $p_{1}=44.4 \%$, we find $s^{*}\left(p_{1}\right)=21.7 \%$ and $s_{1}=20.6 \%$. On the other hand, for the richest quintile (quintile 5 ) with $p_{5}=8.9 \%$, we find $s^{*}\left(p_{5}\right)=23.4 \%$ and $s_{5}=23.1 \%$. Ambiguity causes average saving rates to increase, among both the poor and the rich. Also, the rich continue to save more than the poor after controlling for ambiguity.

\section{Life-Cycle Model with Annuities}

Thus far we have assumed that annuity markets are closed. While survival ambiguity causes a reduction in welfare in our baseline model without annuities, we show that this result is overturned in a world with competitive annuities. Ambiguity distorts consumption away from what the individual would do with full information about survival probabilities, but it also allows competitive insurance companies to pool risks across survival types, unlike a world of full information in which insurance companies can separate 
individuals by survival type. This pooling ensures that welfare is higher in a world with ambiguity. In other words, if the individual can decide just before $t=0$ whether to live in a world with ambiguity (where he will never learn his survival type) or in a world with no ambiguity (where he will learn his survival type at $t=0$ ), then he would choose the world with ambiguity. With ambiguity, competitive annuities provide returns that reflect averaging across survival types, whereas without ambiguity, competitive annuities pay returns that are specific to each type.

This result is reminiscent of Sheshinski (2008, Ch. 8) in which he considers the superiority of long-term annuity contracts that provide risk sharing across survival classes relative to short-term contracts that do not. ${ }^{19}$ His equilibrium with long-term contracts is akin to our equilibrium with ambiguity: insurance companies are unable to sort individuals by risk class and hence there is risk sharing across types. His equilibrium with short-term contracts is akin to our equilibrium without ambiguity: insurance companies sort people by survival type, which eliminates risk sharing.

We set the market rate of interest and the discount rate to zero for simplicity, $r=\rho=0$. There are two survival types as before, but now assume there is no heterogeneity in expectations; everyone faces a probability $p$ of being a low type. Individuals save for retirement by purchasing competitive annuity contracts from insurance companies as in Yaari (1965) but expanded to incorporate ambiguity. The analysis below requires that period utility $u(c)$ be concave $u_{c}>0, u_{c c}<0$.

\subsection{With Ambiguity}

Like individuals, insurance companies cannot separate people by types because that information is unknowable. Instead, they pool everyone together and offer a zero-profit contract that consists of two parts. Annuity assets $a(t)$ are surrendered upon death, and these assets are used to pay a competitive return to saving $^{20}$

$$
r(t)=-\frac{\frac{d}{d t}[p \underline{\Phi}(t)+(1-p) \bar{\Phi}(t)]}{p \underline{\Phi}(t)+(1-p) \bar{\Phi}(t)}
$$

\footnotetext{
${ }^{19}$ Like us, Sheshinski considers ambiguity about survival probabilities. He assumes all individuals share the same, known survival function up to a given age, at which time they learn whether they are a high survival type of a low survival type. Our model is different; individuals never learn their survival probabilities and they use Bayes' rule to update as they age.

${ }^{20}$ The competitive return $r(t)$ can be derived as follows. At each moment a unit mass, infinitely divisible cohort is born. The share of the cohort with low survival type is $p$ and the share with high survival type is $(1-p)$. Then, $p \underline{\Phi}(t)+(1-p) \bar{\Phi}(t)$ is the mass of age $t$ individuals that are alive. Likewise, $-d[p \underline{\Phi}(t)+(1-p) \bar{\Phi}(t)] / d t$ individuals die at age $t$. Collectively, this cohort surrenders the following quantity of annuity contracts, $(-d[p \underline{\Phi}(t)+(1-p) \bar{\Phi}(t)] / d t) a(t)$. The zero profit condition, combined with the assumption that the assets of the deceased are rebated back to survivors of the same age, means that the return to holding annuities $a(t)$ is $r(t)$.
} 
In this case, individuals solve

$$
\max _{c(t)_{t \in[0,1]}}: J^{*}=\int_{0}^{1}[p \underline{\Phi}(t)+(1-p) \bar{\Phi}(t)] u(c(t)) d t
$$

subject to ${ }^{21}$

$$
\begin{gathered}
\frac{d a(t)}{d t}=r(t) a(t)+y(t)-c(t) \\
a(0)=a(1)=0 .
\end{gathered}
$$

The solution is constant consumption as a function of $p$

$$
c^{*}(p)=\frac{\int_{0}^{1}[p \underline{\Phi}(t)+(1-p) \bar{\Phi}(t)] y(t) d t}{\int_{0}^{1}[p \underline{\Phi}(t)+(1-p) \bar{\Phi}(t)] d t} .
$$

\subsection{Without Ambiguity}

Now individuals and insurance companies both have complete information on survival type. Companies separate individuals by type and offer competitive contracts to each type

$$
\begin{aligned}
& \underline{r}(t)=-\frac{\frac{d}{d t} \underline{\Phi}(t)}{\underline{\Phi}(t)} \\
& \bar{r}(t)=-\frac{\frac{d}{d t} \bar{\Phi}(t)}{\bar{\Phi}(t)} .
\end{aligned}
$$

The solution is constant consumption across age but different across type

$$
\begin{gathered}
\underline{c}=\frac{\int_{0}^{1} \underline{\Phi}(t) y(t) d t}{\int_{0}^{1} \underline{\Phi}(t) d t} \\
\bar{c}=\frac{\int_{0}^{1} \bar{\Phi}(t) y(t) d t}{\int_{0}^{1} \bar{\Phi}(t) d t} .
\end{gathered}
$$

\footnotetext{
${ }^{21}$ We are assuming that annuity contracts are infinitely divisible and are bought and sold at unit price. Individuals buy contracts in a competitive insurance market. These contracts pay $r(t)$ per unit held $a(t)$, and there is a fully developed residual annuity market that allows individuals to sell the contract back the insurance industry at the same price.
} 


\subsection{Welfare}

If the individual knows his type, expected utility is

$$
\begin{aligned}
& \underline{J}(\underline{c})=\int_{0}^{1} \underline{\Phi}(t) u(\underline{c}) d t \\
& \bar{J}(\bar{c})=\int_{0}^{1} \bar{\Phi}(t) u(\bar{c}) d t
\end{aligned}
$$

and hence expected utility in a world without ambiguity (a moment before being born into a world without ambiguity) is

$$
J^{n o}=p \underline{J}(\underline{c})+(1-p) \bar{J}(\bar{c}) .
$$

Alternatively, expected utility in a world with ambiguity is

$$
J^{*}=\int_{0}^{1}[p \underline{\Phi}(t)+(1-p) \bar{\Phi}(t)] u\left(c^{*}(p)\right) d t .
$$

Notice that

$$
\begin{aligned}
c^{*}(p) & =\frac{\int_{0}^{1}[p \underline{\Phi}(t)+(1-p) \bar{\Phi}(t)] y(t) d t}{\int_{0}^{1}[p \underline{\Phi}(t)+(1-p) \bar{\Phi}(t)] d t}=\frac{p \underline{c} \int_{0}^{1} \underline{\Phi}(t) d t+(1-p) \bar{c} \int_{0}^{1} \bar{\Phi}(t) d t}{\int_{0}^{1}[p \underline{\Phi}(t)+(1-p) \bar{\Phi}(t)] d t} \\
& =\underline{c} \frac{p \int_{0}^{1} \underline{\Phi}(t) d t}{\int_{0}^{1}[p \underline{\Phi}(t)+(1-p) \bar{\Phi}(t)] d t}+\bar{c} \frac{(1-p) \int_{0}^{1} \bar{\Phi}(t) d t}{\int_{0}^{1}[p \underline{\Phi}(t)+(1-p) \bar{\Phi}(t)] d t} \\
& =\underline{c} \omega+\bar{c}(1-\omega),
\end{aligned}
$$

where

$$
\omega \equiv \frac{p \int_{0}^{1} \underline{\Phi}(t) d t}{\int_{0}^{1}[p \underline{\Phi}(t)+(1-p) \bar{\Phi}(t)] d t} \in(0,1)
$$

and

$$
J^{*}=u(\underline{c} \omega+\bar{c}(1-\omega)) \int_{0}^{1}[p \underline{\Phi}(t)+(1-p) \bar{\Phi}(t)] d t
$$




$$
\begin{aligned}
J^{n o} & =u(\underline{c}) p \int_{0}^{1} \underline{\Phi}(t) d t+u(\bar{c})(1-p) \int_{0}^{1} \bar{\Phi}(t) d t \\
& =u(\underline{c}) \omega \int_{0}^{1}[p \underline{\Phi}(t)+(1-p) \bar{\Phi}(t)] d t+u(\bar{c})(1-\omega) \int_{0}^{1}[p \underline{\Phi}(t)+(1-p) \bar{\Phi}(t)] d t \\
& =(u(\underline{c}) \omega+u(\bar{c})(1-\omega)) \int_{0}^{1}[p \underline{\Phi}(t)+(1-p) \bar{\Phi}(t)] d t .
\end{aligned}
$$

By Jensen's inequality

$$
J^{*}>J^{n o} .
$$

In other words, if the individual can decide just before $t=0$ whether to live in a world with ambi-

guity (where he will never learn his survival type) or in a world with no ambiguity (where he will learn his survival type at $t=0$ ), then he would choose the world with ambiguity. With ambiguity, competitive annuities provide returns that reflect averaging across survival types, whereas without ambiguity, competitive annuities pay returns that are specific to each type.

Ambiguity in isolation could never be welfare improving (recall Definition 1). However, we are not making ceteris paribus comparisons in this section. Instead, the individual's budget constraints are different in the worlds with and without ambiguity, because of our assumption that competitive insurance markets prevail in both worlds.

\subsection{The Individual Welfare Gains from Competitive Annuities}

Recall that ambiguity reduces welfare in the absence of annuity markets and increases welfare in the presence of annuity markets. These two results combine to create a final result: the welfare gains from competitive annuities are larger in a world with ambiguity than in a world without ambiguity. This implies that past studies strictly underestimate the welfare gains from annuitization because they abstract from survival ambiguity. Competitive annuities not only insure survival risk as past studies have established, but they also pool risk across survival type. This second effect strictly enhances the insurance value of annnuitization.

To see this result formally, we introduce some extra notation. In a world with ambiguity, we denote expected utility with annuities $J_{a}^{*}$ and expected utility without annuities $J_{k}^{*}$. The value of annuitization in a world with ambiguity is $V^{*} \equiv J_{a}^{*}-J_{k}^{*}$. Likewise, in a world without ambiguity, we denote expected utility with annuities $J_{a}^{n o}$ and expected utility without annuities $J_{k}^{n o}$, and the value of annuitization is 
$V^{n o} \equiv J_{a}^{n o}-J_{k}^{n o}$. We have already shown that ambiguity reduces welfare in the absence of annuities

$$
J_{k}^{n o}>J_{k}^{*}
$$

and that ambiguity increases welfare in the presence of annuities

$$
J_{a}^{*}>J_{a}^{n o}
$$

Putting these two results together, it must be the case that the welfare gains from annuitization are strictly larger in the presence of ambiguity than without ambiguity

$$
V^{*}>V^{n o}
$$

\section{Conclusion}

Typical life-cycle models assume that individuals know the probability that they will survival to each age. However, in reality the exact survival probabilities facing individuals are likely unknown. In the absence of annuity markets, this type of ambiguity imposes potentially significant costs on individuals because it distorts consumption and saving decisions. Moreover, survival ambiguity is much more costly to the poor than to the rich. However, in the presence of a competitive annuity market, survival ambiguity is actually welfare improving (in an ex ante expected utility sense) because it forces insurance companies to pool risk across unknown survival types. These two results combine to create a third result: the individual welfare gains from competitive annuities are larger in a model with ambiguity than in a typical model that includes only survival risk. 


\section{References}

1. Ameriks, John, Andrew Caplin, and John Leahy (2003), Wealth Accumulation and the Propensity to Plan. Quarterly Journal of Economics 118, 1007-1047.

2. Bagchi, Shantanu (2014), Labor Supply and the Optimality of Social Security. Working Paper, Towson University.

3. Bommier, Antoine (2006), Uncertain Lifetime and Intertemporal Choice: Risk Aversion as a Rationale for Time Discounting. International Economic Review 47(4), 1223-1246.

4. Bommier, Antoine and Bertrand Villeneuve (2012), Risk Aversion and the Value of Risk to Life. Journal of Risk and Insurance, 79(1), 77-104.

5. Brown, Jeffrey R. (2007), Rational and Behavioral Perspectives on the Role of Annuities in Retirement Planning. NBER Working Paper 13537.

6. Brown, Jeffrey R., Arie Kapteyn, Erzo F.P. Luttmer, and Olivia S. Mitchell (2016), Cognitive Constraints on Valuing Annuities. Journal of the European Economic Association, forthcoming.

7. Brown, Jeffrey R., Jeffrey R. Kling, Sendhil Mullainathan, and Marian V. Wrobel (2008), Why Don't People Insure Late-Life Consumption? A Framing Explanation of the underAnnuitization Puzzle. American Economic Review, 98(2), 304-309.

8. Brugiavini, Agar (1993), Uncertainty Resolution and the Timing of Annuity Purchases. Journal of Public Economics 50(1), 31-62.

9. Caliendo, Frank N., Aspen Gorry, and Sita Slavov (2016), The Cost of Uncertainty about the Timing of Social Security Reform. NBER Working Paper 21585.

10. Caliendo, Frank N., Maria Casanova, Aspen Gorry, and Sita Slavov (2016), The Welfare Cost of Retirement Uncertainty. NBER Working Paper 22609.

11. Caliendo, Frank N., Nick L. Guo, and Roozbeh Hosseini (2014), Social Security is NOT a Substitute for Annuities. Review of Economic Dynamics 17, 739-755.

12. Campbell, John Y. (2006), Household Finance. Journal of Finance 61, 1553-1603. 
13. Chai, Jingjing, Wolfram Horneff, Raimond Maurer, and Olivia S. Mitchell (2011), Optimal Portfolio Choice over the Life-Cycle with Flexible Work, Endogenous Retirement, and Lifetime Payouts. Review of Finance 15(4), 875-907.

14. Cocco João F. and Francisco J. Gomes (2012), Longevity Risk, Retirement Savings, and Financial Innovation. Journal of Financial Economics 103(3), 507-529.

15. Cristia, Julian. P. (2009), Rising Mortality and Life Expectancy Differentials by Lifetime Earnings in the United States. Journal of Health Economics 28(5), 984-995.

16. Davidoff, Thomas, Jeffrey R. Brown, and Peter A. Diamond (2005), Annuities and Individual Welfare. American Economic Review 95(5), 1573-1590.

17. De Nardi, Mariacristina, Eric French, and John B. Jones (2010), Why Do the Elderly Save? The Role of Medical Expenses. Journal of Political Economy 118, 39-75.

18. Dimmock, Stephen G., Roy Kouwenberg, Olivia S. Mitchell, and Kim Peijnenburg (2016), Ambiguity Attitudes and Economic Behavior: Results from a US Household Survey. Journal of Financial Economics 119(3), 559-577.

19. Dynan, Karen E., Jonathan Skinner, and Stephen P. Zeldes (2004), Do the Rich Save More? Journal of Political Economy 112(2), 397-444.

20. Edwards, Ryan D. (2008), The Cost of Uncertain Life Span. Journal of Population Economics $26,1485-1522$.

21. Epstein, Larry G. and Michel Le Breton (1993), Dynamically Consistent Beliefs Must Be Bayesian. Journal of Economic Theory 61, 1-22.

22. Finkelstein, Amy and James Poterba (2004), Adverse Selection in Insurance Markets: Policyholder Evidence from the U.K. Annuity Market. Journal of Political Economy 112(1), 183-208.

23. Gan, Li, Guan Gong, Michael Hurd, and Daniel McFadden (2015), Subjective Mortality Risk and Bequests. Journal of Econometrics 188(2), 514-525.

24. Gan, Li, Michael Hurd, and Daniel McFadden (2005), Individual Subjective Survival Curves. Analyses in the Economics of Aging. David Wise (ed). Chicago, University of Chicago Press, 377411. 
25. Gomes, Francisco J., Laurence J. Kotlikoff, and Luis M. Viceira (2007), The Excess Burden of Government Indecision. National Bureau of Economic Research, Working Paper 12859.

26. Grochulski, Borys and Yuzhe Zhang (2013), Saving for Retirement with Job Loss Risk. Economic Quarterly 99, 45-81.

27. Groneck, Max, Alexander Ludwig, and Alexander Zimper (2014), A Life-Cycle Model with Ambiguous Survival Beliefs. SAFE Working Paper No. 73, Goethe University Frankfurt.

28. Heimer, Rawley Z., Kristian Ove R. Myrseth, and Raphael S. Schoenle (2016), YOLO: Mortality Beliefs and Household Finance Puzzles. Working Paper, Federal Reserve Bank of Cleveland.

29. Hosseini, Roozbeh (2015), Adverse Selection in the Annuity Market and the Role for Social Security. Journal of Political Economy 123, 941-984.

30. Huang, H., M.A. Milevsky, and T.S. Salisbury (2011), Yaari's Life Cycle Model in the 21st Century: Consumption Under a Stochastic Force of Mortality. York University Working Paper.

31. Hurd, Michael D. and Kathleen McGarry (1995), Evaluation of the Subjective Probabilities of Survival in the Health and Retirement Study. Journal of Human Resources 30, S268-S292.

32. Kitao, Sagiri (2006), Policy Uncertainty and the Cost of Delaying a Reform: A Case of Aging Japan. Keio University Working Paper.

33. Lucas, Robert E. (2003), Macroeconomic Priorities. American Economic Review 93(1), 1-14.

34. Lusardi, Annamaria, Pierre-Carl Michaud, and Olivia Mitchell (2017), Optimal Financial Literacy and Saving for Retirement. Journal of Political Economy, forthcoming.

35. Lusardi, Annamaria and Olivia S. Mitchell (2007), Baby Boomer Retirement Security: The Roles of Planning, Financial Literacy, and Housing Wealth. Journal of Monetary Economics 54, 205-224.

36. Lusardi, Annamaria and Olivia Mitchell (2008), Planning and Financial Literacy: How Do Women Fare? American Economic Review 98, 413-417.

37. Luttmer, Erzo F. P. and Andrew A. Samwick (2012), The Welfare Cost of Perceived Policy Uncertainty: Evidence from Social Security. Dartmouth College Working Paper. 
38. Mitchell, Olivia S., James M. Poterba, Mark J. Warshawsky, and Jeffrey R. Brown (1999). New Evidence on the Money's Worth of Individual Annuities. American Economic Review 89(5), 1299-1318.

39. Reichling, Felix and Kent Smetters (2015), Optimal Annuitization with Stochastic Mortality and Correlated Medical Costs. American Economic Review 105(11), 3273-3320.

40. Sheshinski, Eytan (2008), The Economic Theory of Annuities. Princeton Press.

41. Sozou, Peter D. (1998), On Hyperbolic Discounting and Uncertain Hazard Rates. Proceedings of the Royal Society of London, B 265, 2015-2020.

42. van Rooij, Maarten, Annamaria Lusardi, and Rob Alessie (2012), Financial Literacy, Retirement Planning and Household Wealth. Economic Journal 122, 449-478.

43. Vidangos, Ivan (2009), Household Welfare, Precautionary Saving, and Social Insurance under Multiple Sources of Risk. Working Paper, Federal Reserve Board.

44. Yaari, Menachem (1965), Uncertain Lifetime, Life Insurance and the Theory of the Consumer. Review of Economic Studies 32(2), 137-150. 


\section{Technical Appendices}

\section{Appendix A: Proofs}

\section{Derivation of Simplified Problem Statement}

Stated formally, the decision maker solves

$$
\max _{u(t)_{t \in[0, T]}}: J=\mathbb{E}\left[\int_{0}^{t_{1}} f(t, u(t), x(t)) d t\right]
$$

subject to

$$
\begin{gathered}
\frac{d x(t)}{d t}=g(t, u(t), x(t)) \text { for } t \in[0, T] \\
x(0)=x_{0}, x(T)=x_{T}
\end{gathered}
$$

$t_{1}$ random with density $\phi\left(t_{1}\right)$ and sample space $[0, T]$

$$
\phi\left(t_{1}\right) \in\left\{\underline{\phi}\left(t_{1}\right), \bar{\phi}\left(t_{1}\right)\right\}, p=\operatorname{prob}\left[\phi\left(t_{1}\right)=\underline{\phi}\left(t_{1}\right)\right],(1-p)=\operatorname{prob}\left[\phi\left(t_{1}\right)=\bar{\phi}\left(t_{1}\right)\right]
$$

This problem can be written as a standard Pontryagin problem (as in the body of the paper) by rewriting $J$ with a change in the order of integration as in Yaari (1965) but expanded to incorporate ambiguity

$$
\begin{aligned}
J & =\mathbb{E}\left[\int_{0}^{t_{1}} f(t, u(t), x(t)) d t\right] \\
& =p \int_{0}^{T} \int_{0}^{t_{1}} \underline{\phi}\left(t_{1}\right) f(t, u(t), x(t)) d t d t_{1}+(1-p) \int_{0}^{T} \int_{0}^{t_{1}} \bar{\phi}\left(t_{1}\right) f(t, u(t), x(t)) d t d t_{1} \\
& =p \int_{0}^{T} \int_{t}^{T} \underline{\phi}\left(t_{1}\right) f(t, u(t), x(t)) d t_{1} d t+(1-p) \int_{0}^{T} \int_{t}^{T} \bar{\phi}\left(t_{1}\right) f(t, u(t), x(t)) d t_{1} d t \\
& =p \int_{0}^{T}\left[\int_{t}^{T} \underline{\phi}\left(t_{1}\right) d t_{1}\right] f(t, u(t), x(t)) d t+(1-p) \int_{0}^{T}\left[\int_{t}^{T} \bar{\phi}\left(t_{1}\right) d t_{1}\right] f(t, u(t), x(t)) d t \\
& =\int_{0}^{T}\left\{p\left[\int_{t}^{T} \underline{\phi}\left(t_{1}\right) d t_{1}\right]+(1-p)\left[\int_{t}^{T} \bar{\phi}\left(t_{1}\right) d t_{1}\right]\right\} f(t, u(t), x(t)) d t
\end{aligned}
$$

and then use the definition $\underline{\Phi}(t)=\int_{t}^{T} \underline{\phi}\left(t_{1}\right) d t_{1}$ and $\bar{\Phi}(t)=\int_{t}^{T} \bar{\phi}\left(t_{1}\right) d t_{1}$. 


\section{Time Consistency under Bayesian Learning}

The following proof is an example of a more general theorem developed by Epstein and Le Breton (1993). Suppose the individual has survived to age $t_{0}$. If so, then he solves the following control problem

$$
\max _{u(t)_{t \in\left[t_{0}, T\right]}}: J=\mathbb{E}\left[\int_{t_{0}}^{t_{1}} f(t, u(t), x(t)) d t\right]
$$

subject to

$$
\begin{aligned}
& \frac{d x(t)}{d t}=g(t, u(t), x(t)) \text { for } t \in\left[t_{0}, T\right] \\
& x\left(t_{0}\right)=x_{t_{0}}, x(T)=x_{T} \\
& t_{1} \text { random with density } \frac{\phi\left(t_{1}\right)}{\Phi\left(t_{0}\right)} \text { and sample space }\left[t_{0}, T\right] \\
& \frac{\phi\left(t_{1}\right)}{\Phi\left(t_{0}\right)} \in\left\{\frac{\phi\left(t_{1}\right)}{\bar{\Phi}\left(t_{0}\right)}, \frac{\bar{\phi}\left(t_{1}\right)}{\bar{\Phi}\left(t_{0}\right)}\right\}, p=\operatorname{prob}\left[\frac{\phi\left(t_{1}\right)}{\Phi\left(t_{0}\right)}=\frac{\phi\left(t_{1}\right)}{\underline{\Phi}\left(t_{0}\right)}\right],(1-p)=\operatorname{prob}\left[\frac{\phi\left(t_{1}\right)}{\Phi\left(t_{0}\right)}=\frac{\bar{\phi}\left(t_{1}\right)}{\bar{\Phi}\left(t_{0}\right)}\right] .
\end{aligned}
$$

Rewrite $J$ by changing the order of integration

$$
\begin{aligned}
& J=\mathbb{E}\left[\int_{t_{0}}^{t_{1}} f(t, u(t), x(t)) d t\right] \\
& =p \int_{t_{0}}^{T} \int_{t_{0}}^{t_{1}} \frac{\phi\left(t_{1}\right)}{\bar{\Phi}\left(t_{0}\right)} f(t, u(t), x(t)) d t d t_{1}+(1-p) \int_{t_{0}}^{T} \int_{t_{0}}^{t_{1}} \frac{\bar{\phi}\left(t_{1}\right)}{\bar{\Phi}\left(t_{0}\right)} f(t, u(t), x(t)) d t d t_{1} \\
& =p \int_{t_{0}}^{T} \int_{t}^{T} \frac{\phi\left(t_{1}\right)}{\underline{\Phi}\left(t_{0}\right)} f(t, u(t), x(t)) d t_{1} d t+(1-p) \int_{t_{0}}^{T} \int_{t}^{T} \frac{\bar{\phi}\left(t_{1}\right)}{\bar{\Phi}\left(t_{0}\right)} f(t, u(t), x(t)) d t_{1} d t \\
& =p \int_{t_{0}}^{T}\left[\int_{t}^{T} \frac{\phi\left(t_{1}\right)}{\underline{\Phi}\left(t_{0}\right)} d t_{1}\right] f(t, u(t), x(t)) d t+(1-p) \int_{t_{0}}^{T}\left[\int_{t}^{T} \frac{\bar{\phi}\left(t_{1}\right)}{\bar{\Phi}\left(t_{0}\right)} d t_{1}\right] f(t, u(t), x(t)) d t \\
& =\int_{t_{0}}^{T}\left\{\frac{p}{\Phi\left(t_{0}\right)}\left[\int_{t}^{T} \underline{\phi}\left(t_{1}\right) d t_{1}\right]+\frac{(1-p)}{\bar{\Phi}\left(t_{0}\right)}\left[\int_{t}^{T} \bar{\phi}\left(t_{1}\right) d t_{1}\right]\right\} f(t, u(t), x(t)) d t \\
& =\int_{t_{0}}^{T}\left\{p \frac{\underline{\Phi}(t)}{\underline{\Phi}\left(t_{0}\right)}+(1-p) \frac{\bar{\Phi}(t)}{\bar{\Phi}\left(t_{0}\right)}\right\} f(t, u(t), x(t)) d t \text {. }
\end{aligned}
$$

Note that the integrand in $J$ above is not proportional to the integrand in $J$ from the initial problem, $\{p \underline{\Phi}(t)+(1-p) \bar{\Phi}(t)\}$.

Now consider how Bayesian updating restores the dynamic consistency property. Let $p\left(t_{0}\right)$ stand for the posterior probability of being a low survival type, from the perspective of time $t_{0}$. Given the prior belief $p(0)$, Bayes' rule gives

$$
p\left(t_{0}\right)=\frac{\underline{\Phi}\left(t_{0}\right)}{p(0) \underline{\Phi}\left(t_{0}\right)+(1-p(0)) \bar{\Phi}\left(t_{0}\right)} \times p(0) .
$$


Take last line from $J$ and replace $p$ with $p\left(t_{0}\right)$ and then, suppressing tedious algebra, we get

$$
\begin{aligned}
J & =\int_{t_{0}}^{T}\left\{p\left(t_{0}\right) \frac{\underline{\Phi}(t)}{\underline{\Phi}\left(t_{0}\right)}+\left(1-p\left(t_{0}\right)\right) \frac{\bar{\Phi}(t)}{\bar{\Phi}\left(t_{0}\right)}\right\} f(t, u(t), x(t)) d t \\
& =\int_{t_{0}}^{T}\left\{\frac{p(0) \underline{\Phi}(t)-p(0) \underline{\Phi}\left(t_{0}\right) \bar{\Phi}(t) / \bar{\Phi}\left(t_{0}\right)}{p(0) \underline{\Phi}\left(t_{0}\right)+(1-p(0)) \bar{\Phi}\left(t_{0}\right)}+\frac{\bar{\Phi}(t)}{\bar{\Phi}\left(t_{0}\right)}\right\} f(t, u(t), x(t)) d t \\
& =\int_{t_{0}}^{T}\left\{\frac{p(0) \underline{\Phi}(t)+(1-p(0)) \bar{\Phi}(t)}{p(0) \underline{\Phi}\left(t_{0}\right)+(1-p(0)) \bar{\Phi}\left(t_{0}\right)}\right\} f(t, u(t), x(t)) d t \\
& \propto \int_{t_{0}}^{T}\{p(0) \underline{\Phi}(t)+(1-p(0)) \bar{\Phi}(t)\} f(t, u(t), x(t)) d t
\end{aligned}
$$

which is the same as the integrand in $J$ from the initial problem. Hence, Bayesian updating ensures dynamic consistency.

\section{Appendix B: Continuous Ambiguity}

In this appendix we generalize our theoretical results and welfare applications to the case of continuous ambiguity rather than the specific binary ambiguity example presented above.

\section{Theory}

Rather than binary ambiguity, suppose the ambiguity is continuous. Suppose ambiguity about survival risk can be summarized by a continuous random variable $\alpha$, that is $\phi\left(t_{1} \mid \alpha\right)$, where $\alpha$ has probability density $\theta(\alpha)$ and support $[0,1]$.

The decision maker solves

$$
\max _{u(t)_{t \in[0, T]}}: J=\mathbb{E}\left[\int_{0}^{t_{1}} f(t, u(t), x(t)) d t\right]
$$

subject to

$$
\begin{gathered}
\frac{d x(t)}{d t}=g(t, u(t), x(t)) \text { for } t \in[0, T] \\
x(0)=x_{0}, x(T)=x_{T}
\end{gathered}
$$

$t_{1}$ random with density $\phi\left(t_{1} \mid \alpha\right)$ and sample space $[0, T]$

$\alpha$ random with density $\theta(\alpha)$ and sample space $[0,1]$.

This problem can be rewritten as a standard Pontryagin problem where $\Phi(t \mid \alpha)=\int_{t}^{T} \phi\left(t_{1} \mid \alpha\right) d t_{1}$. To see this, change the order of integration 


$$
\begin{aligned}
J & =\mathbb{E}\left[\int_{0}^{t_{1}} f(t, u(t), x(t)) d t\right]=\int_{0}^{1} \int_{0}^{T} \int_{0}^{t_{1}} \theta(\alpha) \phi\left(t_{1} \mid \alpha\right) f(t, u(t), x(t)) d t d t_{1} d \alpha \\
& =\int_{0}^{1} \int_{0}^{T} \int_{t}^{T} \theta(\alpha) \phi\left(t_{1} \mid \alpha\right) f(t, u(t), x(t)) d t_{1} d t d \alpha \\
& =\int_{0}^{T}\left[\int_{0}^{1} \theta(\alpha) \int_{t}^{T} \phi\left(t_{1} \mid \alpha\right) d t_{1} d \alpha\right] f(t, u(t), x(t)) d t
\end{aligned}
$$

and then use the definition $\Phi(t \mid \alpha)=\int_{t}^{T} \phi\left(t_{1} \mid \alpha\right) d t_{1}$.

Hence, we have

$$
\max _{u(t)_{t \in[0, T]}}: J=\int_{0}^{T}\left[\int_{0}^{1} \theta(\alpha) \Phi(t \mid \alpha) d \alpha\right] f(t, u(t), x(t)) d t
$$

subject to

$$
\begin{gathered}
\frac{d x(t)}{d t}=g(t, u(t), x(t)) \text { for } t \in[0, T] \\
x(0)=x_{0}, x(T)=x_{T} .
\end{gathered}
$$

Let us define solutions for two separate control problems. First, the decision maker faces ambiguity and second the decision maker knows $\alpha$ and hence knows the survival function $\Phi(t \mid \alpha)$

$$
\begin{gathered}
\left\{u^{*}(t), x^{*}(t)\right\}=\arg \max \left\{\int_{0}^{T}\left[\int_{0}^{1} \theta(\alpha) \Phi(t \mid \alpha) d \alpha\right] f(t, u(t), x(t)) d t\right\} \\
\left\{u^{\alpha}(t), x^{\alpha}(t)\right\}=\arg \max \left\{\int_{0}^{T} \Phi(t \mid \alpha) f(t, u(t), x(t)) d t\right\} .
\end{gathered}
$$

Next we define the objective functionals associated with these two problems

$$
\begin{gathered}
J^{*}(u, x)=\int_{0}^{T}\left[\int_{0}^{1} \theta(\alpha) \Phi(t \mid \alpha) d \alpha\right] f(t, u(t), x(t)) d t \\
J^{\alpha}(u, x)=\int_{0}^{T} \Phi(t \mid \alpha) f(t, u(t), x(t)) d t .
\end{gathered}
$$

With these definitions we are in a position to define the welfare cost of ambiguity.

Definition 2 (Welfare Cost of Continuous Ambiguity). The cost of ambiguity $\Delta$ is the fraction 
of the optimal control that the decision maker would give up to know $\alpha$.

$$
\int_{0}^{1} \theta(\alpha) J^{\alpha}\left(u^{\alpha}(1-\Delta), x^{\alpha}\right) d \alpha=J^{*}\left(u^{*}, x^{*}\right)=\int_{0}^{1} \theta(\alpha) J^{\alpha}\left(u^{*}, x^{*}\right) d \alpha .
$$

Without loss of generality, let $\phi\left(t_{1} \mid \alpha\right)=\alpha \phi\left(t_{1}\right)+(1-\alpha) \bar{\phi}\left(t_{1}\right)$ and hence $\Phi(t \mid \alpha)=\alpha \underline{\Phi}(t)+(1-\alpha) \bar{\Phi}(t)$. Let $\mu_{\alpha}$ and $\sigma_{\alpha}^{2}$ be the mean and variance of the random variable $\alpha$. Then, for any moment in time $t$, the survival function $\Phi(t \mid \alpha)$ is a random variable with moments

$$
\begin{aligned}
\mu_{\Phi}(t)= & \int_{0}^{1} \theta(\alpha) \Phi(t \mid \alpha) d \alpha \\
= & \underline{\Phi}(t) \int_{0}^{1} \theta(\alpha) \alpha d \alpha+\bar{\Phi}(t) \int_{0}^{1} \theta(\alpha)(1-\alpha) d \alpha \\
= & {[\underline{\Phi}(t)-\bar{\Phi}(t)] \mu_{\alpha}+\bar{\Phi}(t) } \\
\sigma_{\Phi}^{2}(t)= & \int_{0}^{1} \theta(\alpha)\left[\Phi(t \mid \alpha)-\mu_{\Phi}(t)\right]^{2} d \alpha \\
= & \int_{0}^{1} \theta(\alpha)\left[\alpha \underline{\Phi}(t)+(1-\alpha) \bar{\Phi}(t)-[\underline{\Phi}(t)-\bar{\Phi}(t)] \mu_{\alpha}-\bar{\Phi}(t)\right]^{2} d \alpha \\
= & {[\underline{\Phi}(t)-\bar{\Phi}(t)]^{2} \sigma_{\alpha}^{2} . }
\end{aligned}
$$

A fair comparison of two decision makers who face ambiguity requires that $\sigma_{\Phi}^{2}(t)$ be constant across

decision makers, for every $t$. From the previous definition, we see that holding $\sigma_{\alpha}^{2}$ fixed across decision makers is sufficient to make a fair comparison.

\section{Application: Life-Cycle Model without Annuities}

Optimal consumption under continuous ambiguity is

$$
\begin{aligned}
c^{*}\left(t \mid \mu_{\alpha}\right) & =\frac{\int_{0}^{1} e^{-r v} y(v) d v}{\int_{0}^{1} e^{-r v+(r-\rho) v / \sigma}\left[\int_{0}^{1} \theta(\alpha) \Phi(v \mid \alpha) d \alpha\right]^{1 / \sigma} d v} e^{(r-\rho) t / \sigma}\left[\int_{0}^{1} \theta(\alpha) \Phi(t \mid \alpha) d \alpha\right]^{1 / \sigma} \\
& =\frac{\int_{0}^{1} e^{-r v} y(v) d v}{\int_{0}^{1} e^{-r v+(r-\rho) v / \sigma}\left[\mu_{\alpha} \Phi(v)+\left(1-\mu_{\alpha}\right) \bar{\Phi}(v)\right]^{1 / \sigma} d v} e^{(r-\rho) t / \sigma}\left[\mu_{\alpha} \underline{\Phi}(t)+\left(1-\mu_{\alpha}\right) \bar{\Phi}(t)\right]^{1 / \sigma}
\end{aligned}
$$


and optimal consumption if you know your type is

$$
\begin{aligned}
c^{\alpha}(t) & =\frac{\int_{0}^{1} e^{-r v} y(v) d v}{\int_{0}^{1} e^{-r v+(r-\rho) v / \sigma} \Phi(v \mid \alpha)^{1 / \sigma} d v} e^{(r-\rho) t / \sigma} \Phi(t \mid \alpha)^{1 / \sigma} \\
& =\frac{\int_{0}^{1} e^{-r v} y(v) d v}{\int_{0}^{1} e^{-r v+(r-\rho) v / \sigma}[\alpha \underline{\Phi}(v)+(1-\alpha) \bar{\Phi}(v)]^{1 / \sigma} d v} e^{(r-\rho) t / \sigma}[\alpha \underline{\Phi}(t)+(1-\alpha) \bar{\Phi}(t)]^{1 / \sigma} .
\end{aligned}
$$

The cost of ambiguity $\Delta$ is

$$
\int_{0}^{1} \theta(\alpha) \int_{0}^{1} \Phi(t \mid \alpha) e^{-\rho t} \frac{\left[c^{\alpha}(t)(1-\Delta)\right]^{1-\sigma}}{1-\sigma} d t d \alpha=\int_{0}^{1}\left[\int_{0}^{1} \theta(\alpha) \Phi(t \mid \alpha) d \alpha\right] e^{-\rho t} \frac{c^{*}\left(t \mid \mu_{\alpha}\right)^{1-\sigma}}{1-\sigma} d t
$$

or

$$
\Delta\left(\mu_{\alpha}\right)=1-\left(\frac{\int_{0}^{1}\left[\mu_{\alpha} \underline{\Phi}(t)+\left(1-\mu_{\alpha}\right) \bar{\Phi}(t)\right] e^{-\rho t} c^{*}\left(t \mid \mu_{\alpha}\right)^{1-\sigma} d t}{\int_{0}^{1} \theta(\alpha) \int_{0}^{1}[\alpha \underline{\Phi}(t)+(1-\alpha) \bar{\Phi}(t)] e^{-\rho t} c^{\alpha}(t)^{1-\sigma} d t d \alpha}\right)^{1 /(1-\sigma)} .
$$

One advantage of assuming that ambiguity is continuous is that we can make a fair comparison (that holds the variance of ambiguity constant across all individuals) and calibrate the model to the quintile survival data all at once, whereas we could only do one or the other in the case of binary ambiguity. The disadvantage of continuous ambiguity is that we cannot pin down the variance of ambiguity in this process. It becomes a free parameter to be assigned exogenously.

The details of our calibration are as follows. We hold $\sigma_{\alpha}^{2}$ exogenously fixed across all decision makers in order to make a fair comparison. Let $\mu_{\Phi}^{i}(t)$ and $\mu_{\alpha}^{i}$ correspond to quintile $i$. We then solve the following calibration problem:

$$
\min _{\Phi(t), \bar{\Phi}(t), \mu_{\alpha}^{i}} \mathcal{L} \equiv \sqrt{\sum_{i=1}^{5} \int_{0}^{1}\left[\Phi_{i}(t)-\mu_{\Phi}^{i}(t)\right]^{2} d t}
$$

or

$$
\min _{\Phi(t), \bar{\Phi}(t), \mu_{\alpha}^{i}} \mathcal{L} \equiv \sqrt{\sum_{i=1}^{5} \int_{0}^{1}\left\{\Phi_{i}(t)-\left[\mu_{\alpha}^{i} \underline{\Phi}(t)+\left(1-\mu_{\alpha}^{i}\right) \bar{\Phi}(t)\right]\right\}^{2} d t}
$$

subject to

$$
\begin{aligned}
& \underline{\Phi}(t)=1-\frac{1}{1+\exp \left[-x_{1}\left(t-x_{2}\right)\right]} \\
& \bar{\Phi}(t)=1-\frac{1}{1+\exp \left[-x_{3}\left(t-x_{4}\right)\right]}
\end{aligned}
$$

which gives 9 parameters to jointly estimate. Notice that the mathematical structure of this problem is identical to the calibration problem in the body of the paper, and hence the $\mu_{\alpha}^{i}$ are the same as the $p_{i}$ from that problem. Table 3 summarize the results of this calibration problem. 
Table 3. Joint Calibration of Survival Functions and Continuous Ambiguity

Shape Parameters of Logistic Survival Curves:

$x_{1}=9.17 \quad x_{2}=0.51 \quad x_{3}=15.23 \quad x_{4}=0.78$

Mean of Random Variable $\alpha$ by Income Quintile:

$$
\mu_{\alpha}^{1}=44.4 \% \quad \mu_{\alpha}^{2}=30.7 \% \quad \mu_{\alpha}^{3}=25.5 \% \quad \mu_{\alpha}^{4}=19.1 \% \quad \mu_{\alpha}^{5}=8.9 \%
$$

Note: $\mu_{\alpha}^{1}$ corresponds to the poorest quintile and $\mu_{\alpha}^{5}$ corresponds to the richest quintile.

Finally, let's suppose $\theta(\alpha)$ follows the beta distribution with pdf

$$
\theta(\alpha)=\frac{\alpha^{\gamma-1}(1-\alpha)^{\beta-1}}{\int_{0}^{1} \alpha^{\gamma-1}(1-\alpha)^{\beta-1} d \alpha}
$$

Recall that the moments are

$$
\begin{gathered}
\mu_{\alpha}=\frac{\gamma}{\gamma+\beta} \\
\sigma_{\alpha}^{2}=\frac{\gamma \beta}{(\gamma+\beta)^{2}(\gamma+\beta+1)} \\
=\mu_{\alpha} \frac{\beta}{(\gamma+\beta)(\gamma+\beta+1)} \\
=\left(\mu_{\alpha}\right)^{2} \frac{\beta}{\gamma(\gamma+\beta+1)} .
\end{gathered}
$$

A fair comparison requires that all decision makers face the same $\sigma_{\alpha}^{2}$, and we can exogenously select this value. Using the means $\mu_{\alpha}^{i}$ from the calibration above, we can pin down $\gamma$ and $\beta$ for each income quintile. From the mean equation

$$
\beta=\gamma\left(\frac{1-\mu_{\alpha}}{\mu_{\alpha}}\right)
$$


and then insert into the variance equation

$$
\begin{aligned}
\sigma_{\alpha}^{2} & =\left(\mu_{\alpha}\right)^{2} \frac{\gamma\left(\frac{1-\mu_{\alpha}}{\mu_{\alpha}}\right)}{\gamma\left(\gamma+\gamma\left(\frac{1-\mu_{\alpha}}{\mu_{\alpha}}\right)+1\right)} \\
& \Longrightarrow \gamma=\frac{\left(\mu_{\alpha}\right)^{2}-\left(\mu_{\alpha}\right)^{3}}{\sigma_{\alpha}^{2}}-\mu_{\alpha} \\
& \Longrightarrow \beta=\left(\frac{\left(\mu_{\alpha}\right)^{2}-\left(\mu_{\alpha}\right)^{3}}{\sigma_{\alpha}^{2}}-\mu_{\alpha}\right)\left(\frac{1-\mu_{\alpha}}{\mu_{\alpha}}\right) .
\end{aligned}
$$

Table 4 summarizes the calibration of the pdfs of the beta distributions for each income quintile, with the assumption that the variance of the random variable $\alpha$ is $\sigma_{\alpha}^{2}=0.1 \%$. Figure 6 plots the pdfs for each quintile, each with a different mean but identical variance to ensure that individuals in different quintiles face identical ambiguity. Note that the variance is very small in this example relative to the case of binary ambiguity.

Table 4. Calibration of Beta PDFs $\theta(\alpha)$ over Continuous Random Variable $\alpha$

Given $\sigma_{\alpha}^{2}=0.1 \%$ and $\mu_{\alpha}^{i}$ from Table 3:

\begin{tabular}{cccccc} 
& Quintile 1 & Quintile 2 & Quintile 3 & Quintile 4 & Quintile 5 \\
\cline { 2 - 6 }$\gamma$ & 109.1863 & 65.0317 & 48.3233 & 29.3186 & 7.1286 \\
$\beta$ & 136.6863 & 146.7475 & 140.8616 & 124.1923 & 72.9588
\end{tabular}

Note: Quintile 1 corresponds to the poorest quintile.

To compute the welfare losses $\Delta\left(\mu_{\alpha}\right)$ for each income quintile, we will follow the assumptions made in the body of the paper: we set the coefficient of relative risk aversion to $\sigma=3$, the utility discount rate to $\rho=0$, and the real interest rate to $2.9 \%$ per year, which in our model implies $r=75 * 0.029=2.175$.

Table 5 reports the welfare cost $\Delta\left(\mu_{\alpha}\right)$ of continuous ambiguity. Notice that these costs are much smaller than in the binary ambiguity case. But this is intentional and not surprising, because we have chosen a very small variance of ambiguity. Individuals don't know their exact survival probabilities, but they are highly confident that their survival probabilities fall into a narrow range. Thus, we would expect the cost of ambiguity to be dramatically smaller than for the case when ambiguity is more pronounced. 
The significant finding here is that ambiguity continues to be highly regressive. The welfare cost to individuals in the poorest quintile is twice the cost to individuals in the richest quintile.

Table 5. Welfare Cost of Continuous Ambiguity by Income Quintile

$$
\Delta\left(\mu_{\alpha}^{1}\right)=0.0034 \% \quad \Delta\left(\mu_{\alpha}^{2}\right)=0.0025 \% \quad \Delta\left(\mu_{\alpha}^{3}\right)=0.0023 \% \quad \Delta\left(\mu_{\alpha}^{4}\right)=0.0020 \% \quad \Delta\left(\mu_{\alpha}^{5}\right)=0.0017 \%
$$

Note: $\mu_{\alpha}^{1}$ corresponds to the poorest quintile and $\mu_{\alpha}^{5}$ corresponds to the richest quintile. 
Figure 1. Calibration of Mortality and Binary Ambiguity by Income Quintile

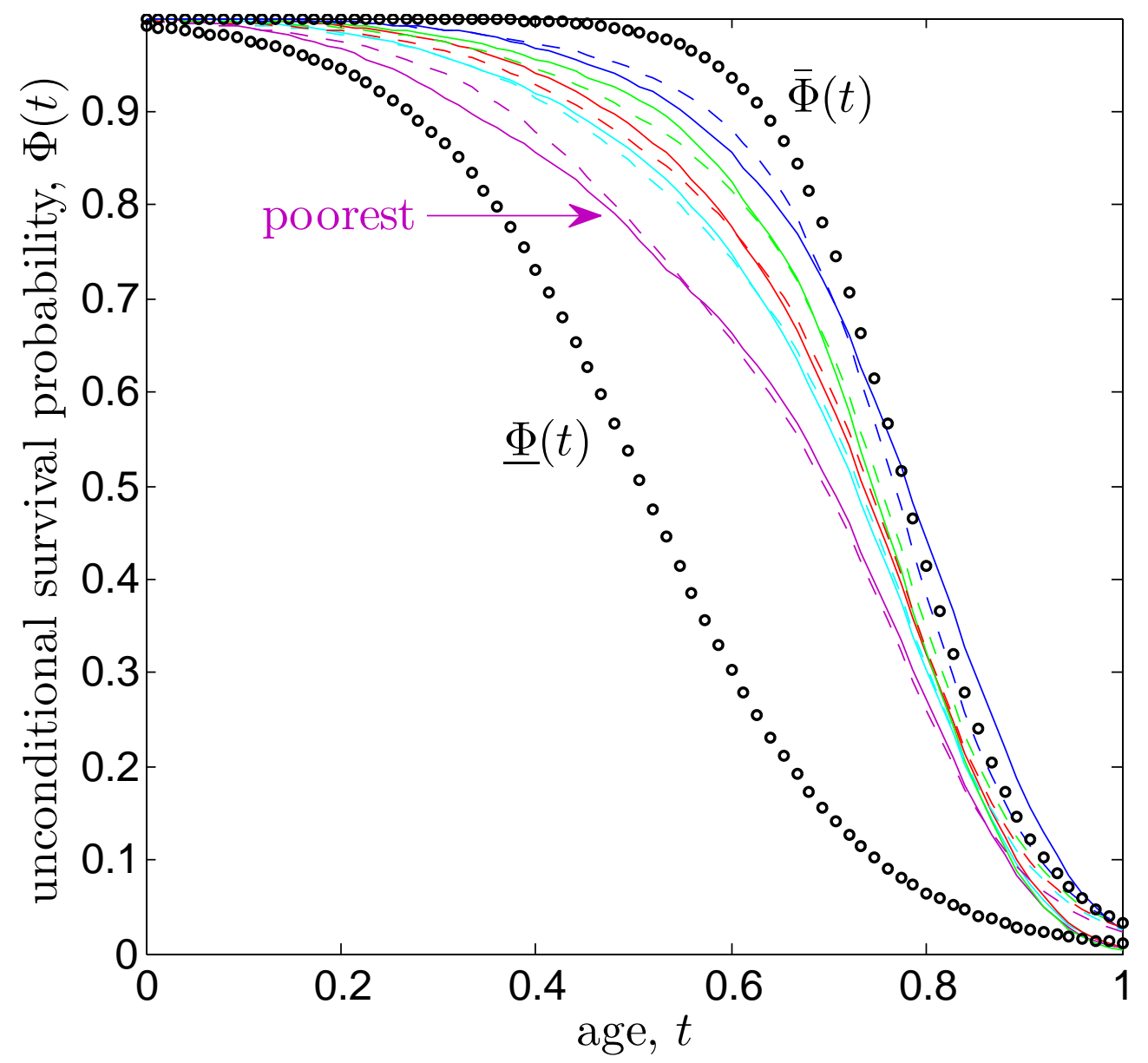

Note: Solid lines are data. Dashes and circles are calibrated. 
Figure 2. Variance of Binary Ambiguity by Age and by Income Quintile

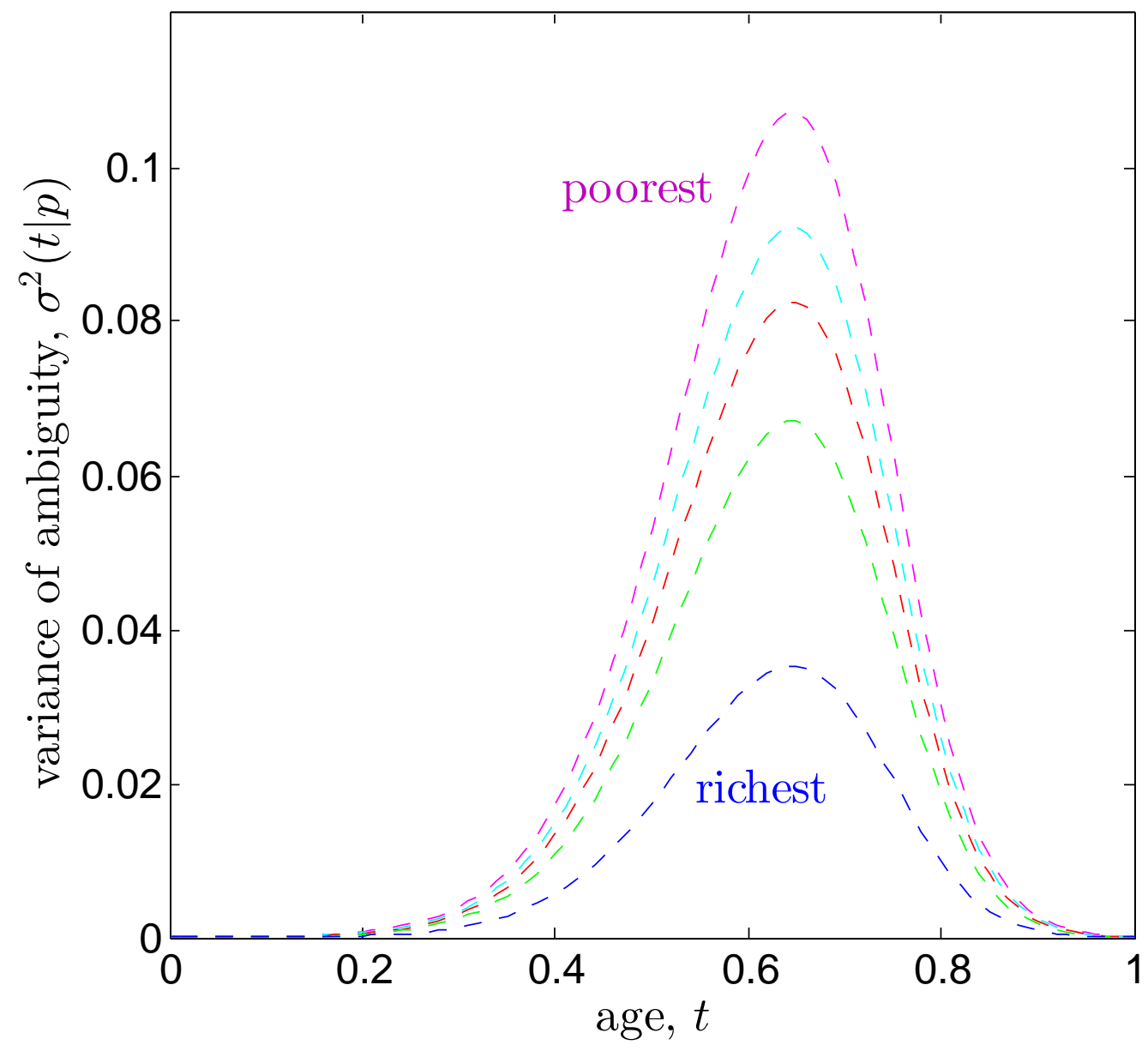

Note: $\sigma^{2}(t \mid p)=(1-p) p[\underline{\Phi}(t)-\bar{\Phi}(t)]^{2}$ 
Figure 3. Consumption under Binary Ambiguity by Income Quintile

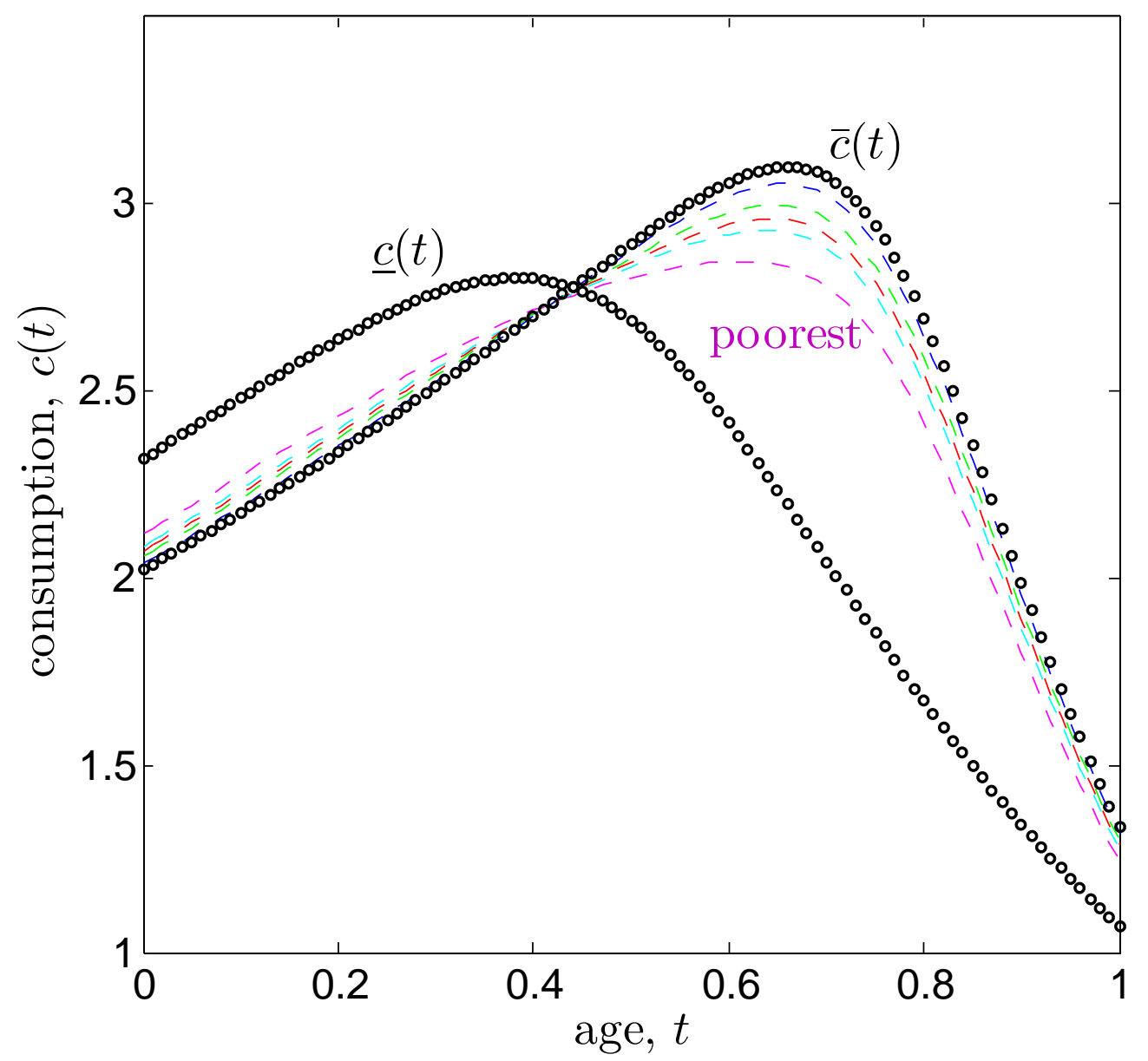

Note: Dashed lines are consumption under ambiguity. Circles are consumption when the health type is known in advance. 
Figure 4. Fair Comparison of Consumption under Binary Ambiguity

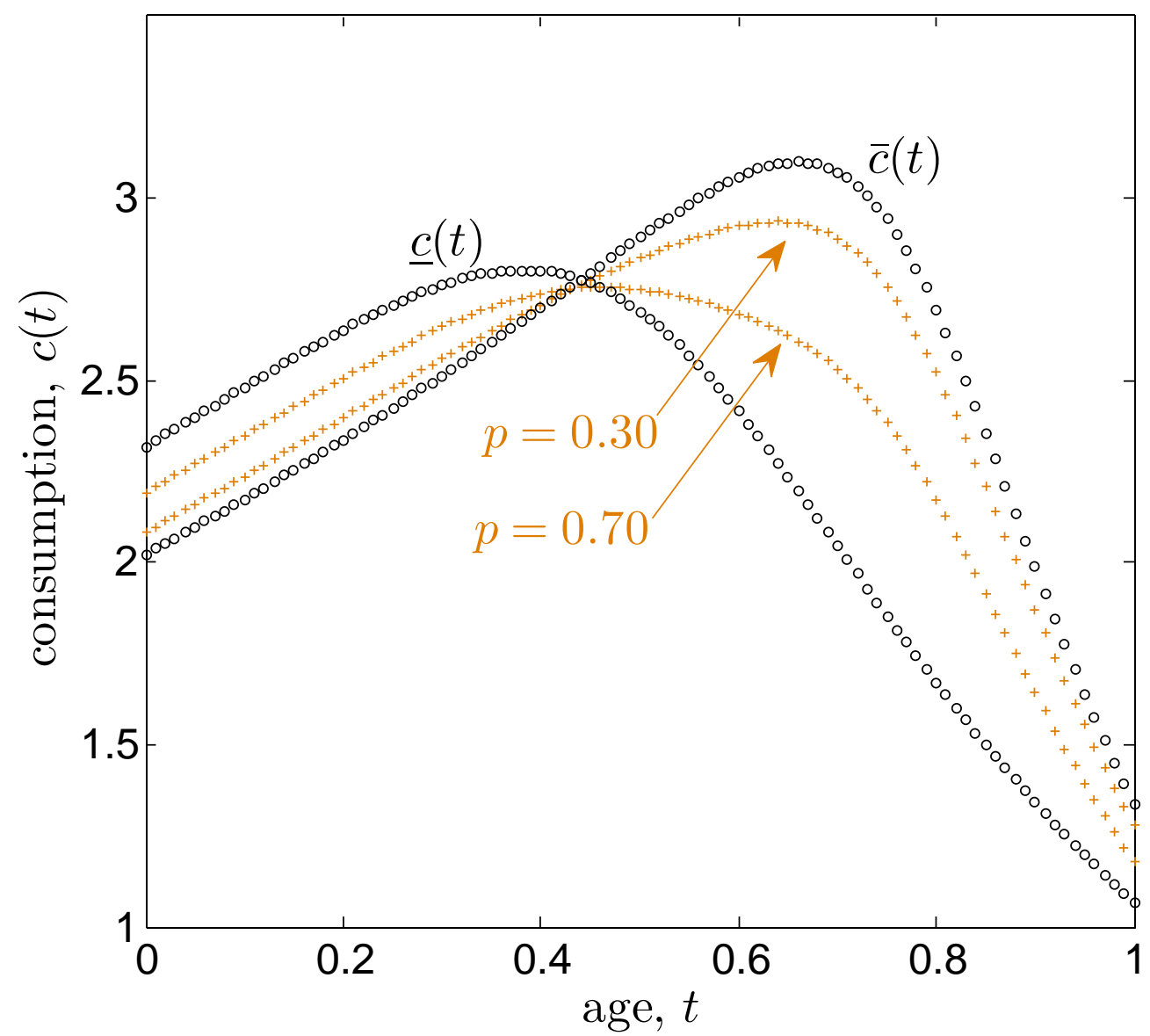

Note: Plus marks are consumption under ambiguity. Circles are consumption when the survival type is known in advance. 
Figure 5. Welfare Cost of Binary Ambiguity

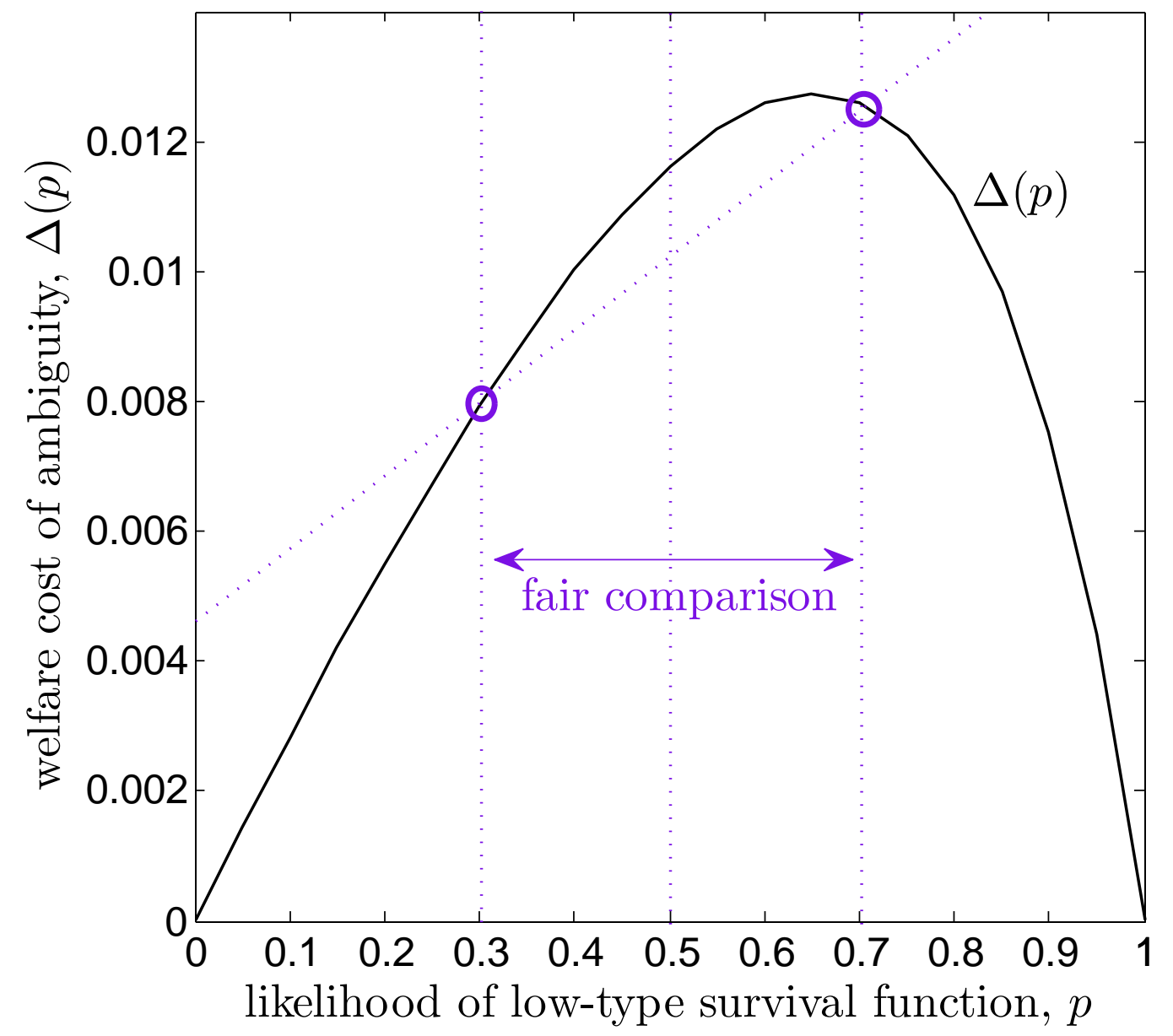

Note: The circles are an example of a fair comparison of two individuals who share the same variance of ambiguity. 
Figure 6. PDF $\theta(\alpha)$ for Continuous Random Variable $\alpha$

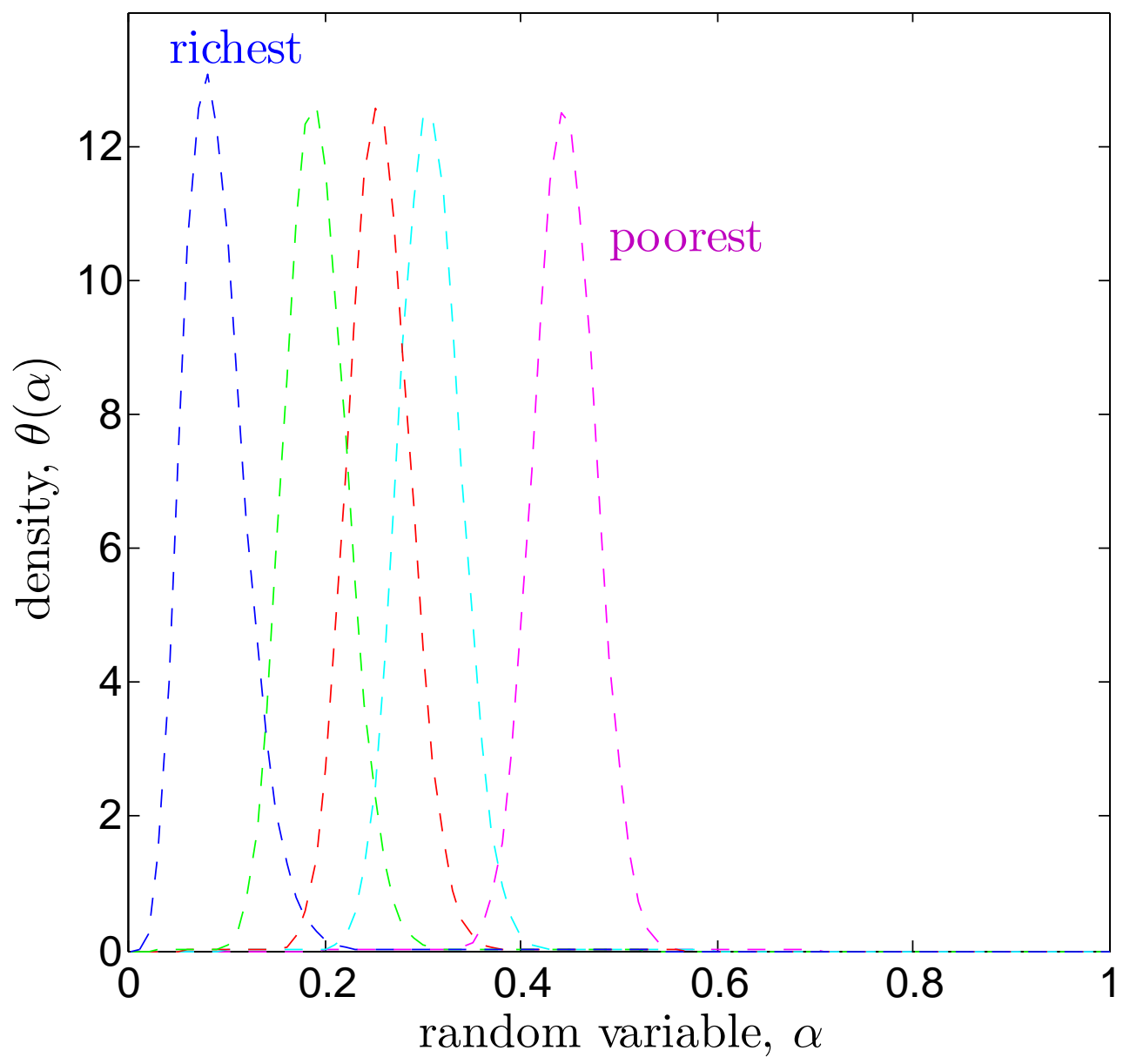

Note: Expected probability of survival to $t: \int_{0}^{1} \theta(\alpha)[\alpha \underline{\Phi}(t)+(1-\alpha) \bar{\Phi}(t)] d \alpha$ 